\title{
The impact of artificial intelligence along the insurance value chain and on the insurability of risks
}

\author{
Martin Eling ${ }^{1} \cdot$ Davide Nuessle $^{1} \cdot$ Julian Staubli ${ }^{1}$
}

Received: 22 July 2019 / Accepted: 7 December 2020 / Published online: 8 February 2021

(c) The Author(s) 2021

\begin{abstract}
Based on a data set of 91 papers and 22 industry studies, we analyse the impact of artificial intelligence on the insurance sector using Porter's (1985) value chain and Berliner's (1982) insurability criteria. Additionally, we present future research directions, from both the academic and practitioner points of view. The results illustrate that both cost efficiencies and new revenue streams can be realised, as the insurance business model will shift from loss compensation to loss prediction and prevention. Moreover, we identify two possible developments with respect to the insurability of risks. The first is that the application of artificial intelligence by insurance companies might allow for a more accurate prediction of loss probabilities, thus reducing one of the industry's most inherent problems, namely asymmetric information. The second development is that artificial intelligence might change the risk landscape significantly by transforming some risks from low-severity/high-frequency to highseverity/low-frequency. This requires insurance companies to rethink traditional insurance coverage and design adequate insurance products.
\end{abstract}

Keywords Artificial intelligence · Insurance · Value chain · Insurability · Technology $\cdot$ Digitalisation

Supplementary Information The online version of this article (https://doi.org/10.1057/s41288-02000201-7) contains supplementary material, which is available to authorized users.

Martin Eling

martin.eling@unisg.ch

Davide Nuessle

davide.nuessle@unisg.ch

Julian Staubli

julian.staubli@unisg.ch

1 Institute of Insurance Economics, University of St. Gallen, Girtannerstrasse 6, 9010 St. Gallen, Switzerland 


\section{Motivation and aim of the paper}

There is a growing consensus on the potential of artificial intelligence to transform modern economies and societies (Abrardi et al. 2019; Bolton et al. 2018; Boyd and Holton 2017; Makridakis 2017) by enabling computer systems to carry out numerous tasks and activities that are typically considered to require human intelligence, thereby significantly improving efficiency and efficacy. At the same time, there is a controversial debate over the risks and limitations of artificial intelligence. ${ }^{1}$

The progress and popularity ${ }^{2}$ of artificial intelligence results from the combination of two developments that enable its productive use. The first is that artificial intelligence has matured, thanks to recent advancements in machine learning and deep learning algorithms (Abrardi et al. 2019). The second is that the availability of big data combined with the rapidly increasing computation power of modern information technology systems accelerates the development and increases the accuracy of artificial intelligence applications (Allam and Dhunny 2019; Thrall et al. 2018). As a result, considerable progress has been made in the capabilities of artificial intelligence in the last few years. ${ }^{3}$ There is a wide range of real-world use cases across industries. Among these are pattern and anomaly detection (e.g. for fraud mitigation, see e.g. Ahmed et al. 2016), speech recognition and natural language generation (e.g. for the development of chatbots, see e.g. Dale 2016), recommendation engines (e.g. for automated product suggestions, see e.g. Marchand and Marx 2020), image recognition (e.g. for improved public safety, see e.g. Zhang et al. 2016), and automated decision-making systems (e.g. for robo-advice, see e.g. Faloon and Scherer 2017).

While some industries such as banking, ${ }^{4}$ healthcare,${ }^{5}$ manufacturing ${ }^{6}$ and software development ${ }^{7}$ have been investing in artificial intelligence for years (Bughin et al. 2017), industry studies note that the insurance sector is lagging behind in the worldwide and intersectoral artificial intelligence movements (Rangwala et al. 2020; Deloitte 2017). Nevertheless, it is likely that artificial intelligence will have a broad impact along the insurance value chain, from underwriting and claims management over distribution and customer service to asset management. Consequently, insurance executives must understand the new technologies that will contribute to this change and how artificial intelligence can help organisations create innovative

\footnotetext{
1 In 2014, Stephen Hawking stated that 'success in creating effective AI [artificial intelligence], could be the biggest event in the history of our civilization. Or the worst. We just don't know' (Kharpal 2017).

${ }^{2}$ Figure A1 in Appendix A in the electronic supplementary material illustrates the exponential growth in the academic interest of artificial intelligence by showing the development of published articles on the subject in Web of Science from 1980 to 2019.

3 In 2016, the programme AlphaGo defeated a human professional player for the first time in the fullsized game Go (Silver et al. 2016). Only 14 years earlier, this was believed to be impossible due to the complexity of the game compared to, for example, chess (Müller 2002).

4 See e.g. Jakšič and Marinč (2019) on the role of artificial intelligence in the banking sector.

5 See e.g. Jiang et al. (2017) and Patel et al. (2009) for an overview of artificial intelligence in medicine.

6 See e.g. Li et al. (2017) and Lee et al. (2018) for applications of artificial intelligence in manufacturing.

7 See e.g. Kothari (2019) for an overview of artificial intelligence applications in software engineering processes.
} 
products, glean valuable insights from new data sources, streamline business processes and improve customer service.

The intention of this paper is to support practitioners in understanding the potential benefits associated with artificial intelligence applications and to motivate academics to study this multifaceted, controversial and heavily under-researched topic. Towards this end, we establish a database of papers and industry studies on the use of artificial intelligence in the insurance sector and systematically evaluate the impact of artificial intelligence along Porter's (1985) value chain and on Berliner's (1982) insurability criteria. Based on the review results, we derive potential future work from practitioners' and researchers' perspectives. In this way, we provide practitioners and academics with a high-level overview of the most important research topics and promote future work in this field. To structure our discussion, the paper is organised into three core steps:

1. Description of artificial intelligence applications that will influence the insurance sector.

2. Analysis of the impact of these applications along the insurance value chain and derivation of benefits for insurance companies as well as insurance customers.

3. Deduction of the consequences for the insurability of risks.

The remainder of this paper is structured as follows. We begin with a short description of our research methodology (Research approach). Then, the literature on the three core research topics is reviewed (Survey of existing knowledge on artificial intelligence in insurance). Finally, the results are summarised and potential areas of future work from both the industry and research perspectives are discussed (Summary and derivation of potential future work).

\section{Research approach}

\section{Literature review}

The literature review consists of a structured search and identification process based on vom Brocke et al. (2009) and Webster and Watson (2002). We review the academic literature by using a search string that includes several keywords in combination with 'insurance' or 'insurer'. The selection of keywords is based on Niu et al. (2016), who conducted a keyword analysis drawing on 20,715 articles on artificial intelligence published between 1990 and 2014. The keywords include terms for disciplines, subdisciplines, techniques and application areas of artificial intelligence. However, as some of the keywords are vague (e.g. 'management', 'identification', 'optimisation') and research on artificial intelligence has developed over the past five years, we have amended the keywords accordingly. ${ }^{8}$ The keywords used in the literature review are summarised in Table 1.

The literature search is conducted in the journal databases EBSCOhost (Business Source Ultimate, Computer Source and EconLit) and ABI/INFORM Collection.

\footnotetext{
${ }^{8}$ See Martínez-Plumed et al. (2018) for a discussion of the keywords provided by Niu et al. (2016).
} 
Table 1 Keywords used in combination with 'Insurance' OR 'Insurer'

\begin{tabular}{lll}
\hline Artificial intelligence & Smart devices & Artificial neural network \\
\hline AI & Genetic algorithm & Swarm intelligence \\
Machine learning & Analytics & Support vector machine \\
Deep learning & Data mining & Computational intelligence \\
Big data & Fuzzy logic & \\
\hline
\end{tabular}

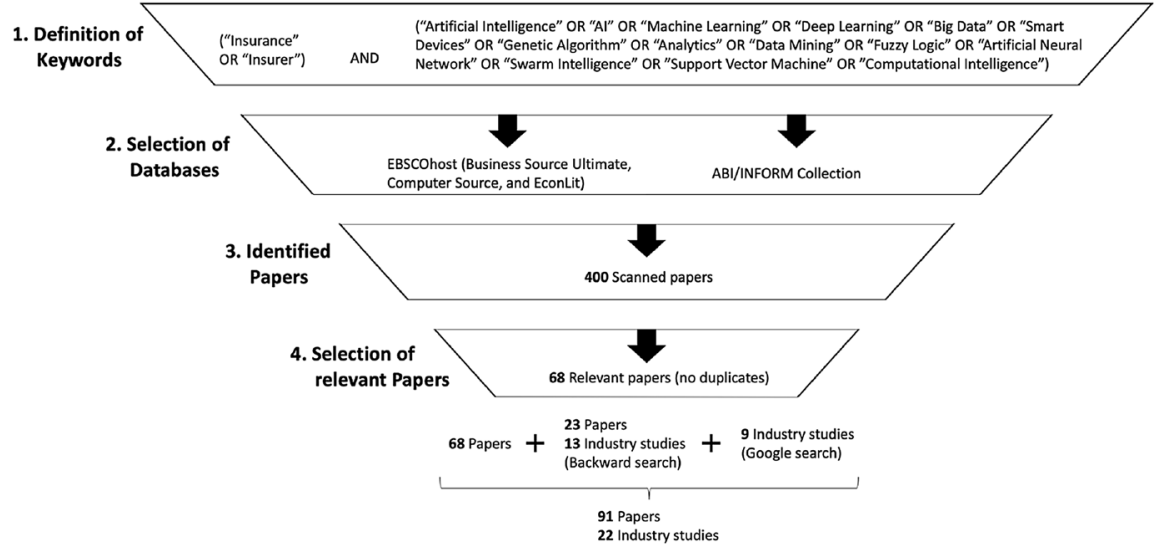

Fig. 1 Literature search process based on vom Brocke et al. (2009) and Webster and Watson (2002)

These databases were chosen because of their focus on business- and economicrelated topics and because they include the relevant insurance-related journals. ${ }^{9}$ The search process (1) was restricted to papers published from 2000 to June 2020, (2) focused on scholarly (peer-reviewed) publications and (3) searched for keywords in the abstract. The search process is displayed in Fig. 1.

In total, exactly 400 publications were found in the two databases. After their examination, 68 papers were identified as relevant for this literature review. A backward search, ${ }^{10}$ as proposed by Webster and Watson (2002), was then conducted, where an additional 2056 sources were screened, and 23 relevant papers and 13 industry studies were found. ${ }^{11}$ Another nine industry studies were identified by

\footnotetext{
9 For example, The Journal of Finance, American Economic Review, Journal of Risk and Insurance, Insurance: Mathematics and Economics, The Geneva Papers on Risk and Insurance-Issues and Practice, The Geneva Risk and Insurance Review, Journal of Insurance Regulation and Risk Management \& Insurance Review.

10 A backward search is the process of screening the references of the initially identified papers.

11 Moreover, all working papers from the annual meetings of the American Risk and Insurance Association (ARIA; for 2012 to 2019), the 2015 World Risk and Insurance Economics Congress and the European Group of Risk and Insurance Economists conferences 2011, 2012, 2013 and 2016 are examined. Surprisingly, no additional sources were identified through this examination, emphasising that there is still a lack of research on these topics in the risk and insurance community.
} 
performing a regular Google search with the defined keywords. Based upon this selection process, a database of 91 papers and 22 industry studies (see Appendix $\mathrm{B}$ in the electronic supplementary material) is developed and the main results are extracted. The 91 papers consist of 86 journal articles and five trade journal articles. Based on their content, the papers were assigned to the respective stage in the insurance value chain (see Table B1 in the electronic supplementary material). ${ }^{12}$ Industry studies could not be mapped to a single step of the value chain because they discuss the impact of artificial intelligence on the entire insurance industry and across the value chain, so for them a separate list (see Table B2 in the electronic supplementary material) has been created.

\section{Conceptual frameworks: value chain and insurability criteria}

Following Eling and Lehmann (2018), we use two conceptual frameworks to illustrate our results. The first, Porter's (1985) value chain, distinguishes a firm's primary from supporting activities in delivering a product or service; because Porter's (1985) value chain was not formulated for a specific industry and was intended to be a rather general concept, we adapt it using the insurance-specific value chain by Rahlfs (2007) (see Fig. 2).

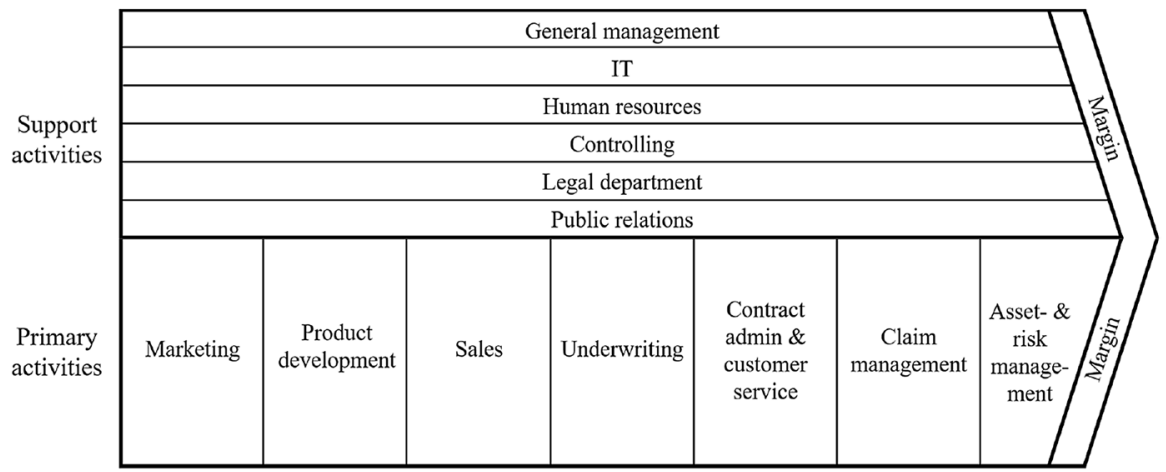

Fig. 2 Insurance-specific value chain based on Porter (1985) and Rahlfs (2007)

\footnotetext{
12 The focus of research on artificial intelligence in the insurance sector is on claim management and underwriting and pricing. A quantitative examination of the number of identified papers per stage of the value chain shows that $38 \%$ of the 91 papers address the application of artificial intelligence in claim management, while $26 \%$ assess the usage of artificial intelligence in underwriting and pricing. The other value chain stages have a percentage share below $10 \%$, indicating that the application of artificial intelligence in these areas is still heavily under-researched (see Table C1 in Appendix C in the electronic supplementary material for more details).
} 
Table 2 Insurability criteria and related requirements defined by Berliner (1982)

Insurability criteria

\begin{tabular}{lll}
\hline Actuarial (1) Randomness of loss occurrence & Independence and predictability of loss exposure \\
& (2) Maximum possible loss & Manageable \\
& (3) Average loss per event & Moderate \\
& (4) Loss exposure & Loss exposure must be large enough \\
& (5) Information asymmetry & Moral hazard and adverse selection not excessive \\
Market & (6) Insurance premium & Cost recovery (insurer) and affordability (policyholder) \\
& (7) Cover limits & Acceptable \\
Society & (8) Public policy & Consistent with social values \\
& (9) Legal restrictions & Allow the coverage \\
\hline
\end{tabular}

We then analyse Berliner's (1982) insurability criteria, a frequently used and comprehensive approach for differentiating insurable and uninsurable risks. Nine insurability criteria cover five actuarial, two market-specific and two societal aspects of insurability (see Table 2). This approach has been used, for example, by Biener et al. (2015) to analyse the insurability of cyber risks, by Charpentier (2007) to scrutinise the insurability of climate risks and by Gehrke (2014) to evaluate agricultural production risks. We refer to Berliner $(1982,1985)$ and Biener et al. (2015) for further details on the criteria.

\section{Survey of existing knowledge on artificial intelligence in insurance}

The digitalisation ${ }^{13}$ of the insurance industry is already quite advanced and has gone far beyond the transition from analogue to digital information processing (Stoeckli et al. 2018). Eling and Lehmann (2018) describe digitalisation as 'the integration of the analogue and digital worlds with new technologies that enhance customer interaction, data availability, and business processes'. Digital transformation is also driven by InsurTechs, ${ }^{14}$ which have emerged in the last decade (Riikkinen et al. 2018). New technologies affecting the insurance industry include cloud computing, ${ }^{15}$ telematics, the Internet of Things (IoT) ${ }^{16}$ mobile phones, blockchain

\footnotetext{
${ }^{13}$ Digitalisation is often used interchangeably with digitisation (see e.g. BarNir et al. 2003). However, a clear distinction should be made between the two. While digitisation is the technical process of converting analogue data into digital forms, digitalisation describes the adoption of digital technologies in various contexts (Legner et al. 2017). These two developments lead to digital transformation, which triggers profound changes in business and society (Majchrzak et al. 2016; Vial 2019).

${ }^{14}$ InsurTech encompasses the emerging technologies, innovative business models, applications, processes and products that might transform the traditional insurance sector (International Association of Insurance Supervisors 2017). For an overview of the InsurTech landscape see e.g. Braun and Schreiber (2017).

${ }^{15}$ See e.g. Akhusama and Moturi (2016) who analysed cloud computing uses in terms of productivity applications, business applications, infrastructure on-demand, finance applications, core business applications and databases in insurance companies in Kenya.

16 The Internet of Things can be defined as a 'collection of smart devices that interact on a collaborative basis to fulfil a common goal' (Sicari et al. 2015).
} 
technology, ${ }^{17}$ artificial intelligence and predictive modelling (Cappiello 2020). Digitalisation has already had a considerable impact along the insurance value chain and will continue to do so as new technologies emerge and mature (Eling and Lehmann 2018). ${ }^{18}$ Key changes comprise enhanced process efficiency, improved underwriting and product development, reshaped customer interactions and distribution strategies and new business models (Albrecher et al. 2019). Bohnert et al. (2019) show in their study that digitalisation activities have a significantly positive impact on the business performance of insurance companies. ${ }^{19}$

At the beginning of the digitalisation wave, the main focus was on online and digital distribution channels (Garven 2002) and their impact on insurance agents (Eastman et al. 2002a, 2002b), customers (Kaiser 2002) and competition (Brown and Goolsbee 2002). In the ensuing years, the ubiquity of mobile and interconnected devices exponentially increased the availability of customer data. ${ }^{20}$ The extensive amount of available data has opened up new opportunities for insurance companies to apply innovative technologies for their benefit. For this reason, access to the vast amount of customer data forms the basis for numerous artificial intelligence applications and can be considered a precondition for the implementation of artificial intelligence by insurance companies.

\section{What is artificial intelligence and which technologies will influence the insurance industry?}

The first developments concerning artificial intelligence began more than 60 years ago with the construction of the first 'thinking machines': computer systems with human-like intelligence equalling, and at some point, exceeding that of human beings (Baum et al. 2011; Lake et al. 2016). To test a machine's ability to exhibit intelligent, humanoid behaviour, the Turing test was invented (Turing 1950). ${ }^{21}$ The first definitions of the term 'artificial intelligence' date from this time. However, as a result of the various conceptions and the rather vague nature of (human) intelligence, there is no widely accepted definition of artificial intelligence but rather a multitude of coexisting definitions (Wang 2019; see also Bhatnagar et al. 2018; Monett and Lewis 2018). ${ }^{22}$

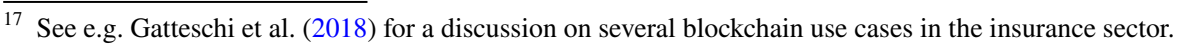

18 See also The Geneva Association (2018) for a discussion of the impact of digital technologies on insurance and the role of insurance in an increasingly digitised economy.

19 See Bohnert et al. (2019) for an analysis of the relationship between the expression of a digital agenda in annual reports and the business performance of 41 publicly-traded European insurance companies for the time period 2007 to 2017.

20 The collected data include traditional, structured, transactional data as well as contemporary, unstructured, behavioural data, commonly referred to as 'Big Data' and characterised by its volume, velocity, variety, veracity and value (Erevelles et al. 2016; Lycett 2013). Big Data might, for example, simplify the detection of insurance fraud (Bologa et al. 2013).

21 Turing (1950) proposed that a machine has reached intelligent behaviour once a human evaluator cannot tell whether or not he or she was engaged in natural conversation with another human or with a machine.

22 See Wang (2019) for a discussion of the difficulties in defining artificial intelligence.
} 
McCarthy (2007), who played a leading role in coining the term artificial intelligence in 1955, describes it as the science and engineering of manufacturing intelligent machines. Barr and Feigenbaum (1981) describe artificial intelligence in more detail as the part of computer science concerned with designing intelligent computer systems, systems that exhibit characteristics associated with intelligence in human behaviour such as understanding written and spoken language, learning, reasoning or solving problems. A survey by Monett and Lewis (2018) asked professionals and experts worldwide to comment on hundreds of definitions of artificial intelligence. The most accepted definition was Wang's (2008): 'The essence of intelligence is the principle of adapting to the environment while working with insufficient knowledge and resources. Accordingly, an intelligent system should rely on finite processing capacity, work in real-time, open to unexpected tasks, and learn from experience. This working definition interprets intelligence as a form of relative rationality.' For the purpose of this paper, we base our understanding of artificial intelligence on Kelley et al.'s (2018) more comprehensive description of artificial intelligence as 'a computer system that can sense its environment, comprehend, learn, and take action from what it is learning'. 23

The premise of artificial intelligence applications is to train computer systems with large amounts of data obtained through IoT and other big data sources to recognise patterns and apply their learned abilities to new data sets. The three types of artificial intelligence-categorised by their degree of intelligence ${ }^{24}$ - are narrow, general and super (Kaplan and Haenlein 2019). Artificial narrow intelligence systems are trained to perform very specific physical or cognitive tasks; they operate within a limited context and a predefined range. In contrast, artificial general intelligence works on broader problem areas and has the capacity to assess its surroundings and give emotionally-driven responses comparable to those of humans. Artificial super intelligence systems, which exhibit the potential to outperform humans across a wide range of disciplines, have not yet been developed and are very likely still decades away (Jajal 2018). Table 3 summarises the three types of artificial intelligence.

Table 3 Types of artificial intelligence (Kaplan and Haenlein 2019)

\begin{tabular}{lll}
\hline $\begin{array}{l}\text { Artificial narrow intelligence } \\
\text { (weak AI) }\end{array}$ & $\begin{array}{l}\text { Artificial general intelligence } \\
\text { (strong AI) }\end{array}$ & $\begin{array}{l}\text { Artificial super intelligence } \\
\text { (conscious/self-aware AI) }\end{array}$ \\
\hline $\begin{array}{l}\text { Application of AI to specific areas } \\
\text { only }\end{array}$ & $\begin{array}{c}\text { Application of AI to several } \\
\text { areas }\end{array}$ & Application of AI to any area \\
$\begin{array}{c}\text { Inability to autonomously solve prob- } \\
\text { lems in other areas }\end{array}$ & $\begin{array}{c}\text { Ability to autonomously solve } \\
\text { problems in other areas }\end{array}$ & $\begin{array}{c}\text { Ability to solve problems in } \\
\text { other areas instantaneously }\end{array}$ \\
$\begin{array}{l}\text { Outperformance of humans in a } \\
\text { specific area }\end{array}$ & $\begin{array}{c}\text { Outperformance of humans in } \\
\text { several areas }\end{array}$ & $\begin{array}{c}\text { Outperformance of humans in } \\
\text { all areas }\end{array}$ \\
\hline
\end{tabular}

\footnotetext{
${ }^{23}$ See Appendix D in the electronic supplementary material for a summary of definitions of artificial intelligence.

24 There are many definitions of intelligence. Grewal (2014) defines intelligence as 'a general mental ability for reasoning, problem solving, and learning'. The term intelligence generally refers to the ability to acquire and apply different skills and knowledge to solve a problem (Neisser et al. 1996).
} 
Compared to classical rule-based systems, where data is strictly processed as initially defined through programming rules, artificial intelligence algorithms can learn and improve themselves independently based on past experiences (Kreutzer and Sirrenberg 2020). The method used to train these algorithms and thus realise artificial intelligence is machine learning. It consists of four types of learning: supervised, semi-supervised, unsupervised and reinforcement (Gentsch 2018; Kreutzer and Sirrenberg 2020). The most common type of machine learning is supervised learning, which requires humans to define each element of the input and output data. The algorithm is then trained to find the connection between the input and output variables of the data set, so that the answers are derived as precisely as possible. The second most common type is unsupervised learning, which does not include predefined output variables. The aim of the algorithms is to identify patterns and structures among the input variables independently. Semi-supervised and reinforcement learning are rather rare, and we refer to Kreutzer and Sirrenberg (2020) for their explanation.

Over the past few years, deep learning has gained increasing attention in artificial intelligence research. Deep learning, ${ }^{25}$ which was not widely accepted as a viable form of artificial intelligence until 2012 (Krizhevsky et al. 2017), is a subset of (unsupervised) machine learning. While conventional machine learning techniques are limited in processing raw data, deep learning allows the processing of data from a wider range of data sources and requires less human effort to pre-process data (LeCun et al. 2015). Due to the increasing volume and complexity of data and the rapid development of modern computing, deep learning has recently become increasingly popular (Yu et al. 2018). ${ }^{26}$ In the last decade, deep learning has made significant progress in numerous fields (Yuan et al. 2019) such as speech recognition (see e.g. Graves et al. 2013), image classification (see e.g. Rawat and Wang 2017; Yu et al. 2017; He et al. 2016), language translation (see e.g. Young et al. 2018), object recognition (see e.g. Krizhevsky et al. 2017) and detection (see e.g. Ren et al. 2017 and Redmon and Farhadi 2017), and has outperformed other machine learning techniques. Even though the predictive accuracy of artificial neural networks has greatly improved, the networks' internal logic often remains inexplicable and incomprehensible due to their inherent complexity (Knight 2017; Castelvecchi 2016). ${ }^{27}$ Most of the discussions among insurance practitioners with regard to applying artificial intelligence for parts of their value creation still focus on conventional

\footnotetext{
25 See e.g. LeCun et al. (2015). In a deep learning neural network, a digitised input (e.g. an image or speech) proceeds through multiple layers (typically from 5 to 1000) of connected 'neurons', of which each responds to a different feature of the input and an output is ultimately provided (Topol 2019). Neural networks are defined as 'neuron-like processing units that collectively perform complex computations' (Lake et al. 2016). As the name suggests, this artificial intelligence method originates in neuroscience. Initially, research on artificial intelligence was intertwined with neuroscience and psychology (Churchland and Sejnowski 1988; Marblestone et al. 2016). The first attempts to construct artificial neural networks that could compute logical functions were made in the 1940s (McCulloch and Pitts 1943). There are manifold types of deep learning neural network algorithms. For reviews see e.g. Goodfellow et al. (2016) and Yu et al. (2018).

26 Unlike classical neural networks, deep learning applies more hidden layers, resulting in superior processing of complex data with manifold structures (Goodfellow et al. 2016).

27 Due to these opaque decision-making systems, deep learning is often described as a 'Black Box System' (Guidotti et al. 2018).
} 
machine-learning-enabled applications, as deep learning is still in the development phase and cannot yet be reliably deployed and implemented across a wide range of tasks (Panetta 2018). However, deep learning is expected to have a significant impact on the insurance industry as it requires very little human engineering to benefit from the increasing amount of available data and computation power.

To date, there is no common description of the different application fields of artificial intelligence. Some experts have created IT-related categories such as 'machine learning', 'modelling' or 'problem-solving' (see e.g. Görz et al. 2013; Russell and Norvig 2012). However, Kreutzer and Sirrenberg (2020) see machine learning and deep learning not as independent fields of application but rather as the basis of artificial intelligence usage. They define natural language processing, natural image processing/computer vision, expert systems and robotics as the four major application fields of artificial intelligence. They further note that many artificial intelligence applications, such as autonomous vehicles, represent a mixed form of these applications.

Table 4 summarises insurance-relevant artificial intelligence applications based on a systematic assessment of all the 91 papers and 22 industry studies (see Appendix B in the electronic supplementary material), explains them and maps specific industry use cases. The applications cover the full process from accessing to processing data and from evaluating to deploying data for enhanced decision-making or process optimisation. Many high-level applications across the value chain, such as automated claims management, combine multiple artificial intelligence applications such as text analysis and natural language processing, image and video analysis, as well as pattern and anomaly detection.

The use cases show that most applications in the insurance industry, ranging from the analysis of images of customers through the use of algorithms for the estimation of contractual terms for life insurance policies to the optimisation of fraud detection, aim to realise artificial narrow intelligence (weak AI) as they solve very specific tasks. In light of today's insurance markets, insurance companies are thus more interested in applications of artificial narrow intelligence than in mimicking human intelligence (strong AI). The impact of more human-like artificial general intelligence on the insurance industry remains unknown as the technology is not yet fully understood and developed. For now, insurance companies should focus on the implementation of artificial narrow intelligence while monitoring the technological developments of artificial general intelligence. Most applications focus on specific areas of the value chain and are used for customer and operations efficacy: scenarios where the computational advantage, speed and accuracy of artificial intelligence are mainly levered. Using artificial intelligence to generate new insights or to reveal previously unknown results is more difficult to realise from a technological point of view (Deloitte 2017). Today's most prominent use cases in this category are telematics-enabled usage-based insurance contracts in the health, motor and property and casualty segment. ${ }^{28}$ Start-ups such as Oscar $^{29}$ use machine learning algorithms,

\footnotetext{
28 See e.g. Ayuso et al. (2019) for a discussion on improving automobile insurance ratemaking using telematics by incorporating mileage and driver behaviour data.

29 https://www.hioscar.com/.
}

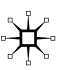




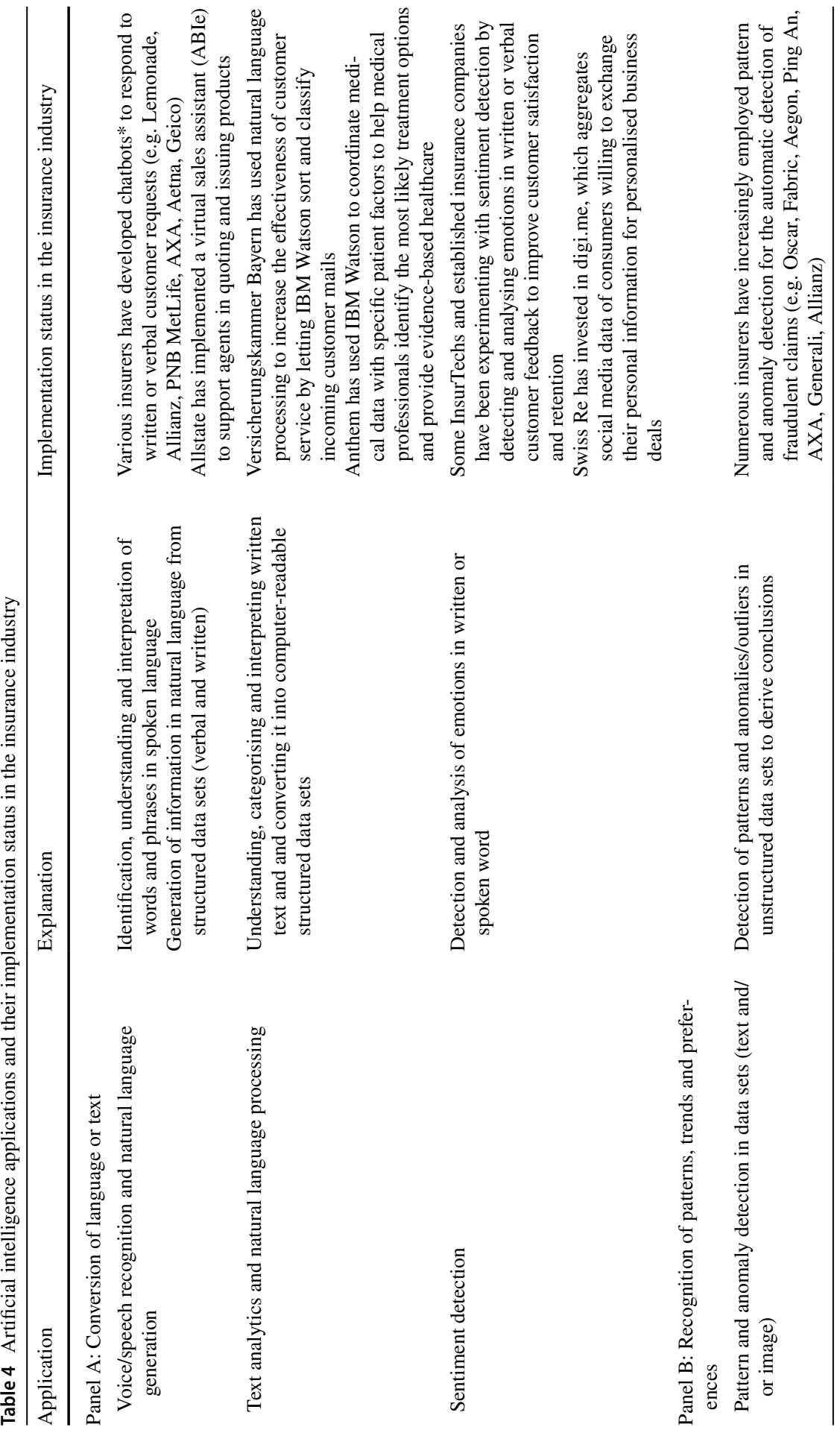




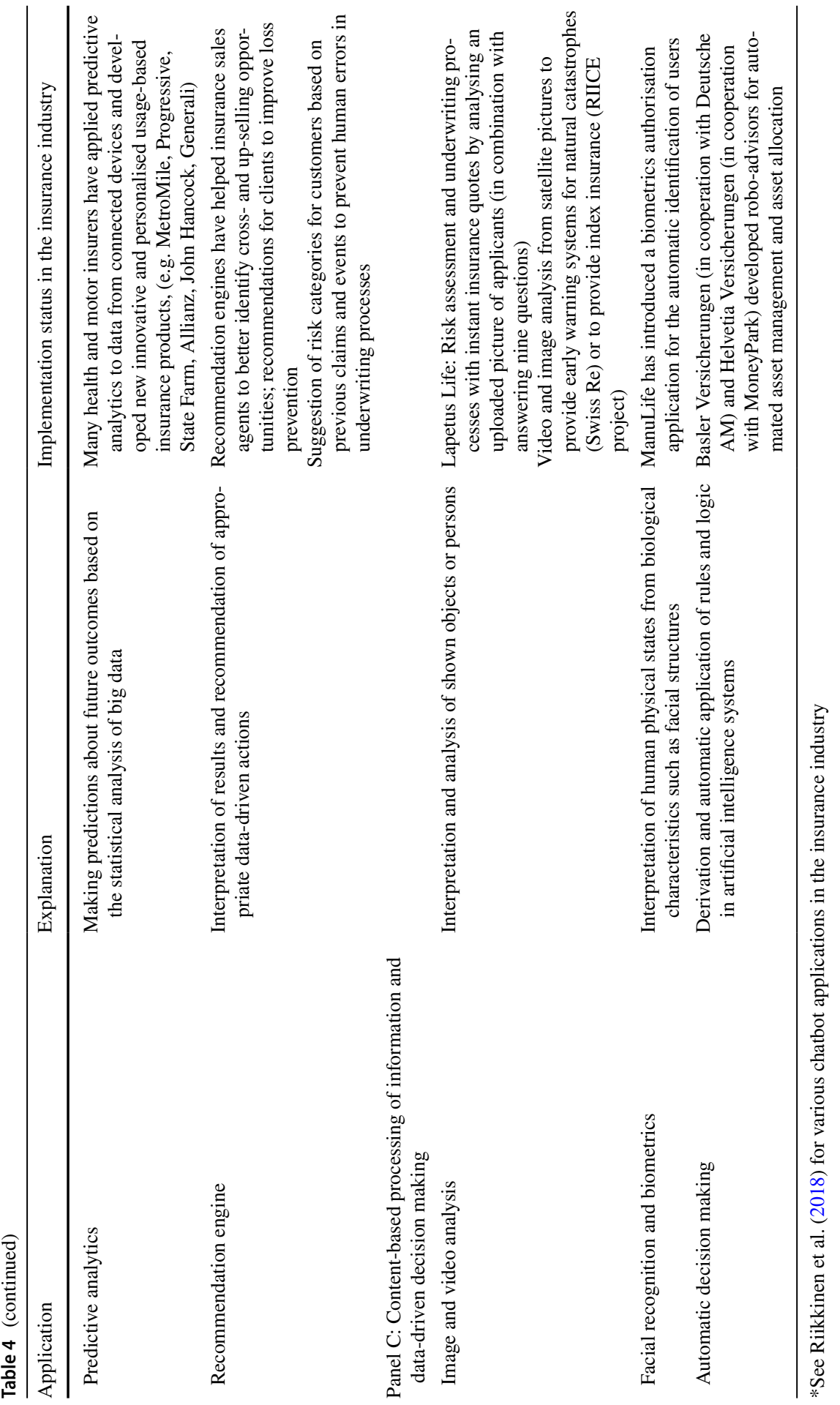

称。 
for instance, to analyse claim data and make inferences about the frequency of certain activities and procedures doctors perform. Based on the results, Oscar is able to identify experts and specialists in certain treatments to refer policyholders to the most suitable hospital. As another example, Lemonade ${ }^{30}$ is changing several links in the traditional insurance value chain by replacing brokers, underwriting agents, service employees and fraud detection experts with artificial intelligence systems.

\section{What is the impact of artificial intelligence along the insurance value chain?}

We continue our systematic assessment of all 91 papers and 22 industry studies to summarise the impact of artificial intelligence applications along the insurance-specific value chain (Table 5 ). ${ }^{31}$

There are three principal categories of change initiated by artificial intelligence systems (see Eling and Lehmann 2018). The first is the way in which insurance companies interact with their customers (e.g. sales, customer service) is being transformed. While customer services traditionally required personal interaction with an agent, broker or bank for customer queries and product information due to a lack of alternatives, the information available has improved significantly over the internet and/or via chatbots. Some products can even be purchased online via chatbots without any personal interaction. This enables insurance companies to deploy human sales and customer service agents more effectively as chatbots take over some of their tasks. The insureds benefit through the availability of customer service and product information at any time and at a higher speed. Further along the value chain, digital technologies, such as apps, offer assistance and support claims reporting. Especially important is the use of artificial intelligence in risk reduction and prevention, for example, by proactive customer outreach in a risky situation. This enables the insurance industry to evolve from a 'detect and repair' to a 'predict and prevent' mode (Kelley et al. 2018). If implemented, this might lead to a completely new business model: preventing losses through a comprehensive risk management solution rather than compensating losses (The Geneva Association 2018). Such a development has the potential to decrease overall losses, which would not only benefit insurance companies and insureds, but also economic welfare.

The second change is the automation of business processes (e.g. processing of contracts, reporting of claims) and decisions (e.g. underwriting, claim settlement, product offerings). While transaction-intensive industries such as health insurance are already using background processing, the use of big data and

\footnotetext{
30 https://www.lemonade.com/.

31 In Appendix E (see electronic supplementary material), we combine Tables 4 and 5 into a 'value chain and technology matrix'.
} 


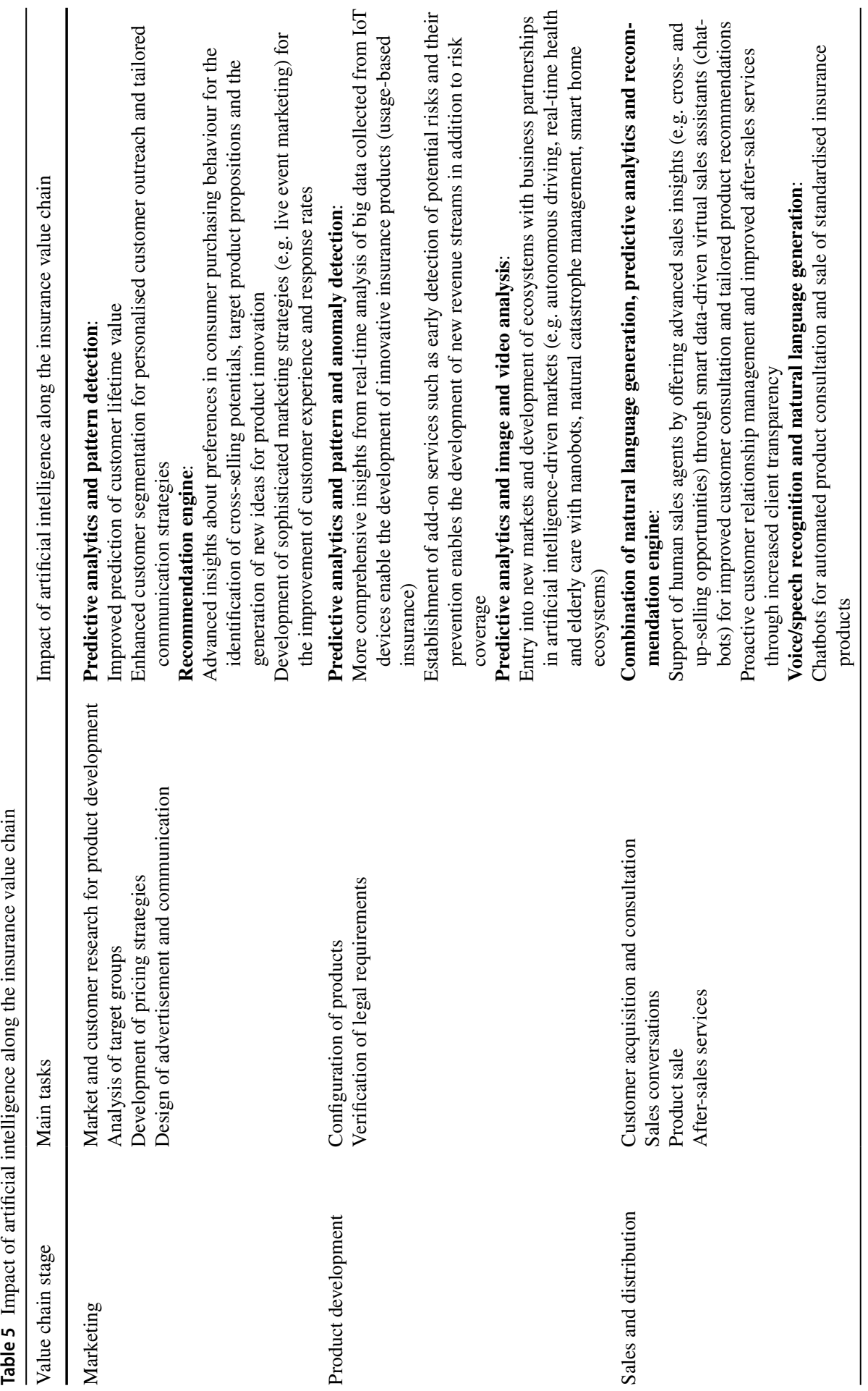

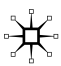




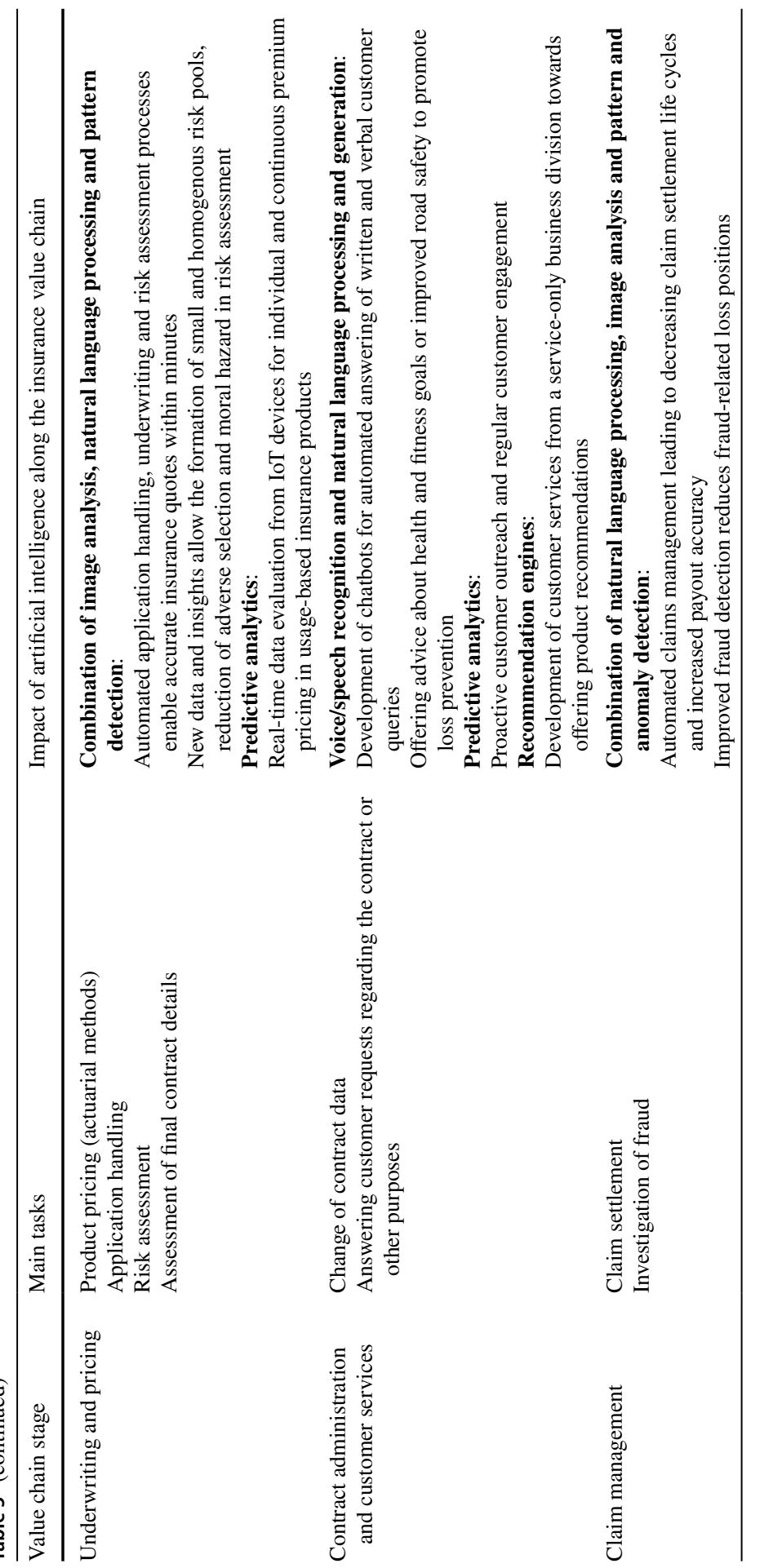




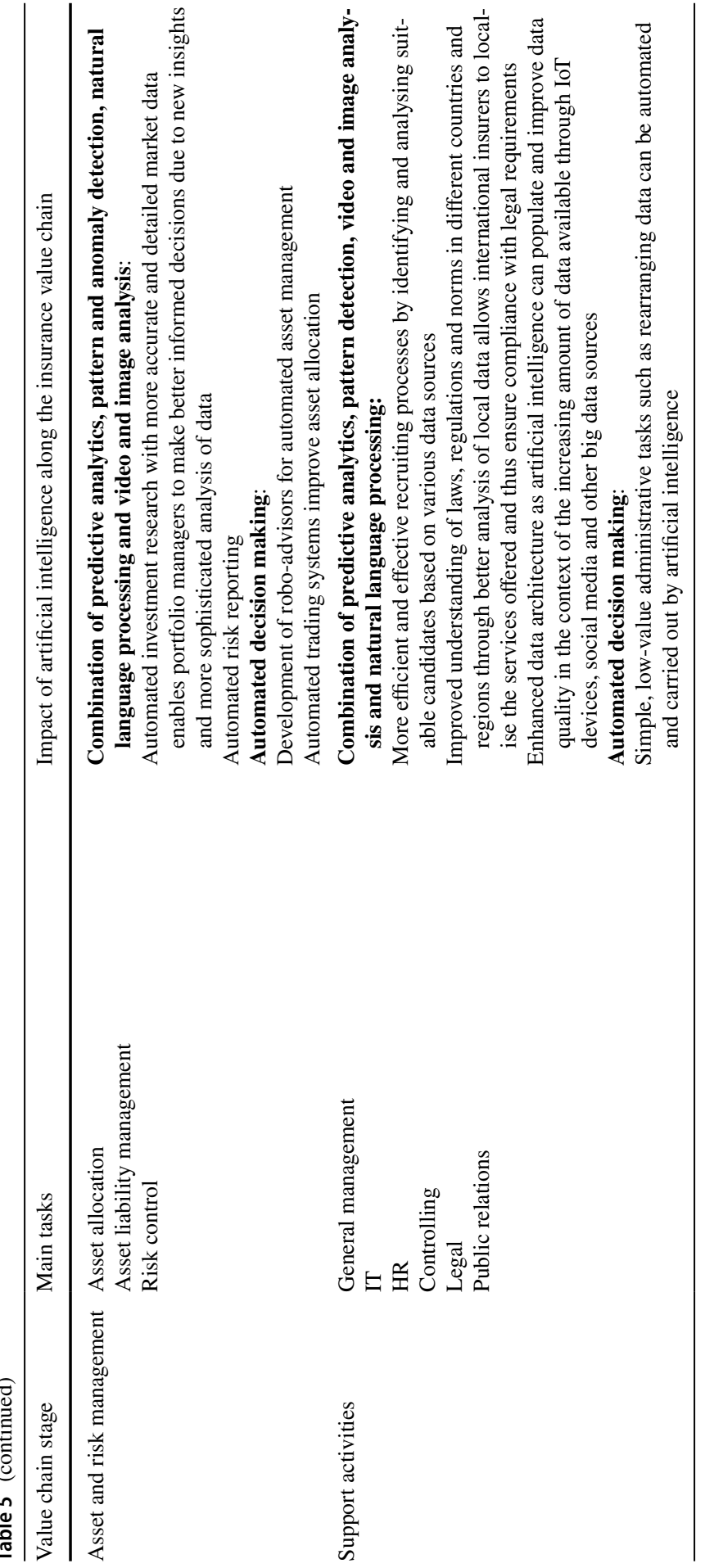

称。 
artificial intelligence will stimulate a further wave of automation. The biggest benefits of automation for insurance companies are potential cost savings. Furthermore, a higher accuracy for administrative repetitive tasks can be achieved by eliminating human errors and skilled employees will have more time to concentrate on truly value-adding tasks. Automation in the reporting and settlement of claims will accelerate business processes, leading to greater customer satisfaction. As artificial intelligence applications can process and analyse large amounts of data generated by telematic devices, social networks or other internet sources (e.g. customer feedback, pictures, videos) in, for example, the underwriting process, insureds may have to answer fewer questions, which increases their satisfaction and hence has a positive impact on customer retention. One major challenge with the use of big data and artificial intelligence in this context is the accompanying ethical and legal issues. These include discussions about the extent to which insurers are allowed to use all of the generated data for decision making, how long the data has to be retained and which actions insurers must take to protect the data against, for instance, cybercrime (Hussain and Prieto 2016).

While the first two categories of change are closely related to the impact of artificial intelligence along the insurance value chain, as discussed in Table 5, the third category includes fundamental changes in insurance markets, which have not been discussed so far. The development of artificial intelligence will not only create new insurance markets and new risks but also cause certain existing markets to disappear (The Geneva Association 2018). One obvious example is autonomous driving, which changes the nature of liability in the automotive industry. Who is liable in case of an accident: the passenger, the car manufacturer or the software developer of the artificial intelligence algorithms? This development questions whether traditional car insurance, as we know it today, will still exist in the future. Cyber risks arising from the use of artificial intelligence technologies are also generating new market opportunities, with some industry studies predicting that cyber risk insurance might become the largest non-life segment in 2032 (e.g. KPMG 2018).

In addition to the impact of artificial intelligence in each single stage of the insurance value chain, the combination of these changes will have profound implications for the entire insurance landscape. The increasing prevalence of digital technologies in society causes traditional industry borders to blur. The resulting ecosystems will significantly influence the future of the insurance industry. ${ }^{32}$ Ecosystems can be understood as 'an interconnected set of services that allow users to fulfil a variety of needs in one integrated experience' (Catlin et al. 2018). The most relevant ecosystems for the insurance industry include

\footnotetext{
${ }^{32}$ Catlin et al. (2018) expect the emergence of 12 major ecosystems which will account for approximately USD 60 trillion in revenues by 2025 . This highlights the significant impact of ecosystems on the global economy.
} 
the mobility, home and health ecosystems. These ecosystems offer insurance companies the opportunity to not only enter new revenue streams by reconsidering their traditional roles in the economy but also to integrate their insurance products into seamless customer journeys (Lorenz et al. 2020). While insurance companies currently have a passive and limited relationship with insureds, the emergence of ecosystems might cause significant changes in the way they interact with customers and how they distribute their products and services. In the mobility ecosystem, for example, insurance companies face the opportunity to expand their services to areas such as the purchase of vehicles, parking, traffic management and car sharing (Catlin et al. 2018). The potential benefits of ecosystems for insurance companies further include increased customer retention, improved loss prevention to reduce claims and lower distribution costs (Lorenz et al. 2020).

Table 6 summarises the major benefits of artificial intelligence applications for insurance companies and customers along the value chain. The results in Table 6 are derived from our findings in Table 5. As previously mentioned, the reduction of insurance costs-whether through decreasing loss payments or transaction costs-is beneficial both for the shareholders of insurance companies and for the insureds. Lower insurance costs will increase the insurer's profitability, leading to a higher shareholder value, but will also reduce premiums if passed on to the insureds (which can be assumed in competitive markets). Regardless of which case occurs (depending on the competitive situation), the reduction of insurance costs ultimately leads to an increase in economic welfare. 


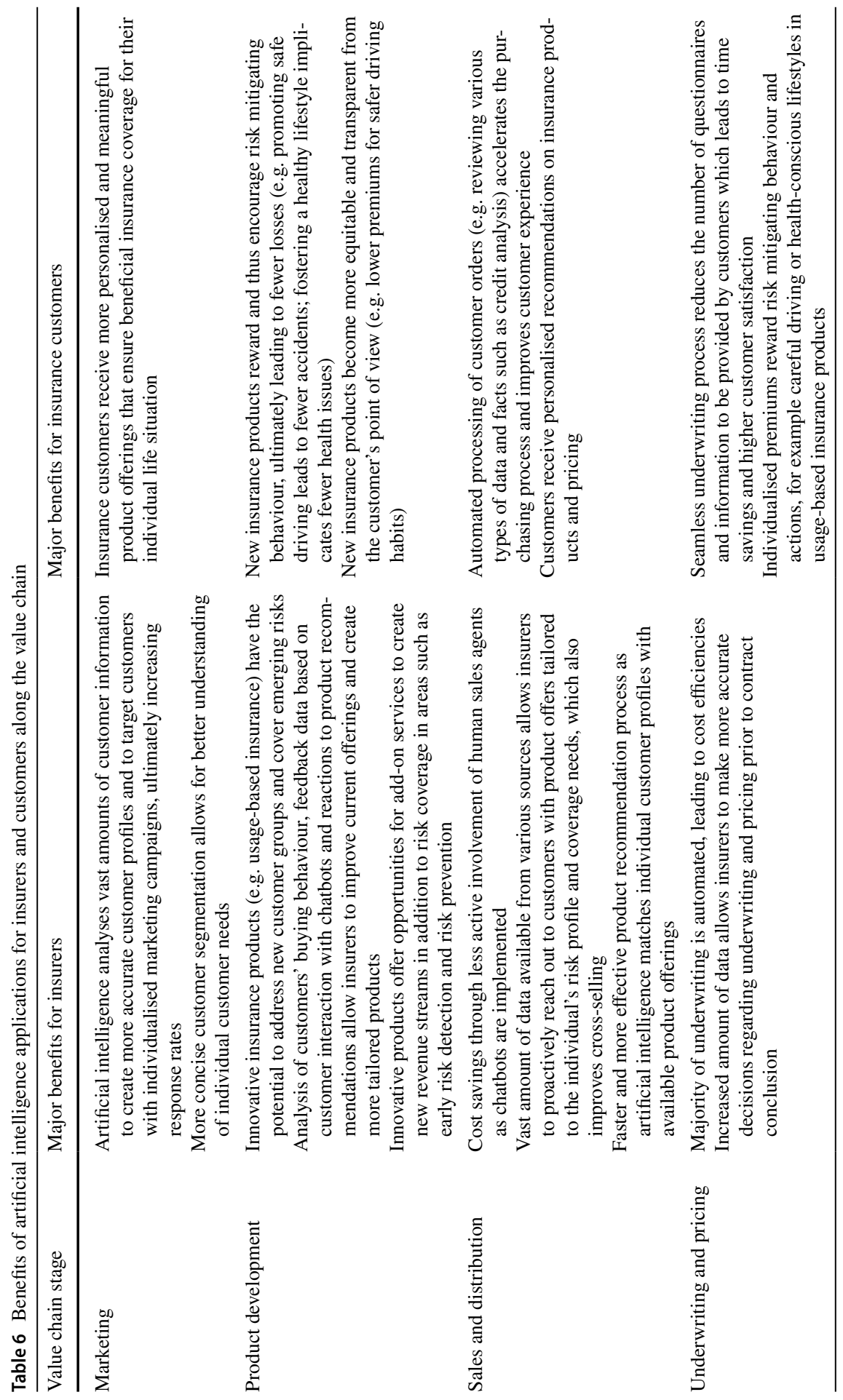




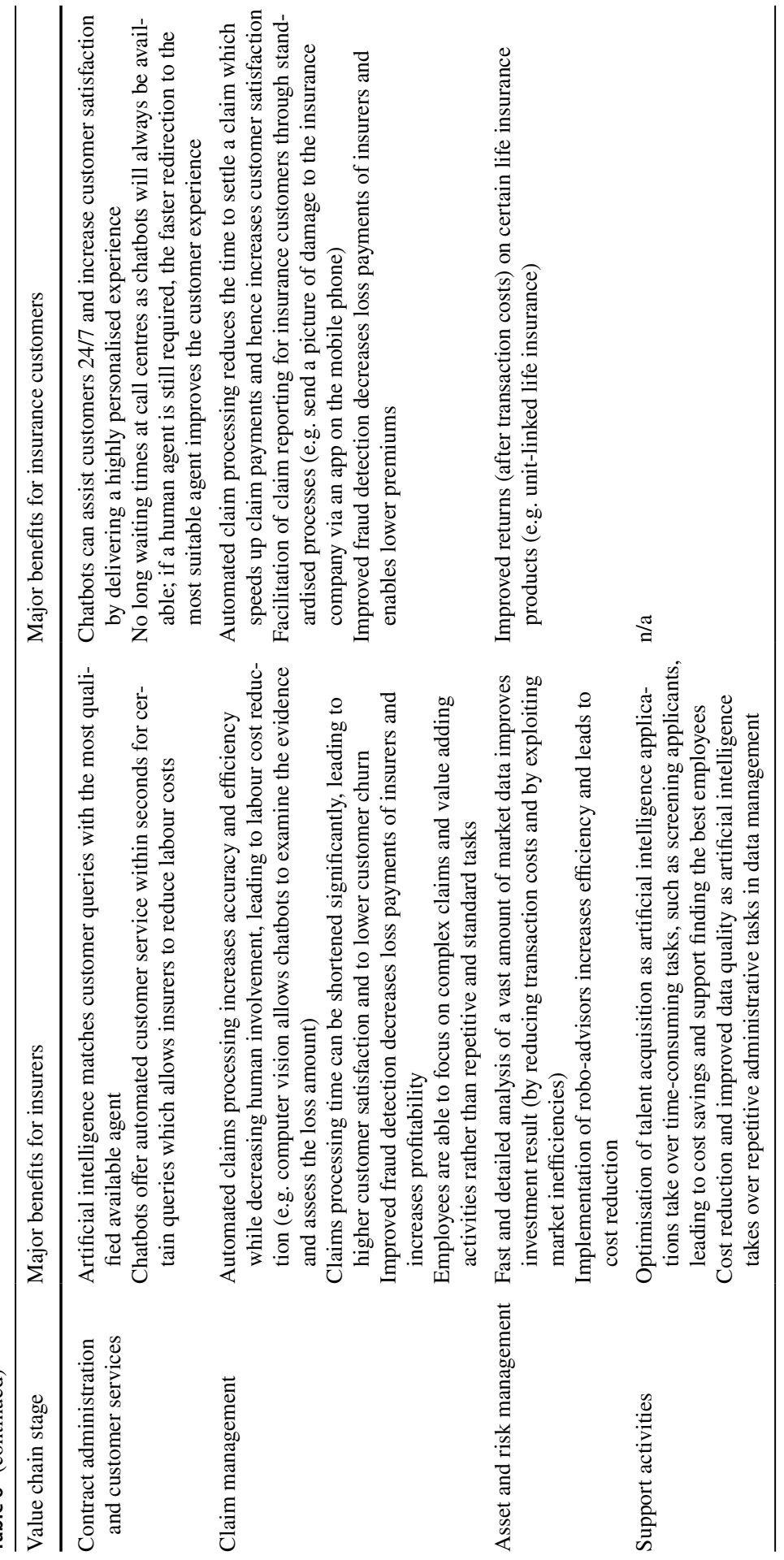

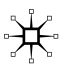




\section{How does artificial intelligence influence the insurability of risks?}

Table 7 summarises the expected influence of artificial intelligence on the insurability of risks structured along Berliner's (1982) insurability criteria. The results in Table 7 are deduced from our results in Tables 4 and 5. The assessment distinguishes between (a) the application of artificial intelligence by insurance companies themselves and (b) the changes in the risk landscape triggered by artificial intelligence. The results show that the application of artificial intelligence by insurers does not compromise but rather improves the insurability of risks. The only exception is criterion 8 , public policy, which remains unclear as the application of artificial intelligence implies increased transparency of policyholders' sensitive data, which potentially raises ethical and moral questions. However, the change in the risk landscape as a result of the increasing implementation of artificial intelligence poses many challenges to the insurability of risks and raises numerous questions for all insurability criteria.

The heterogenous results underline that a clear distinction between the application of artificial intelligence by insurers and the changes in risks triggered by artificial intelligence is of utmost importance. For this reason, we divide our subsequent discussion into these two categories.

\section{Application of artificial intelligence by insurers}

In light of today's insurance markets, the application of artificial intelligence by insurance companies shows three major effects in the context of the insurability of risks. The increasing availability of detailed risk-relevant information about policyholders through historical and real-time data sets will change traditional actuarial risk assessment and pricing models. The granular analysis of texts, images and videos from internal and external databases, as well as from connected devices (i.e. telematics devices and health wearables), allows insurance companies to more accurately estimate and predict loss probabilities and loss amounts on an individual level. This enables insurance companies to distinguish good and bad risks more precisely and thus reduce adverse selection. Additionally, it might even give those with bad risks an incentive to increase loss prevention efforts or to change their behaviour; hence, it also reduces moral hazard (e.g. usage-based insurance products). It further allows insurance companies to form small and homogenous risk groups with accurate and adaptive premium pricing schemes for each policyholder as risk-relevant behaviour, including prevention effort, is transparent and directly measurable. Consequently, bad risks will pay a higher and good risks a lower premium. This, however, raises questions related to the affordability of premiums for bad risks, which potentially contradicts insurance criterion 6 .

In addition, the acquisition, processing and storage of sensitive customer data by insurance companies must be compliant with data privacy and security laws, as well as with moral and ethical considerations. Sensitive customer data is the basis of numerous artificial intelligence applications and it is thus crucial for insurance companies to ensure compliance with legal frameworks (e.g. GDPR). For this reason, 


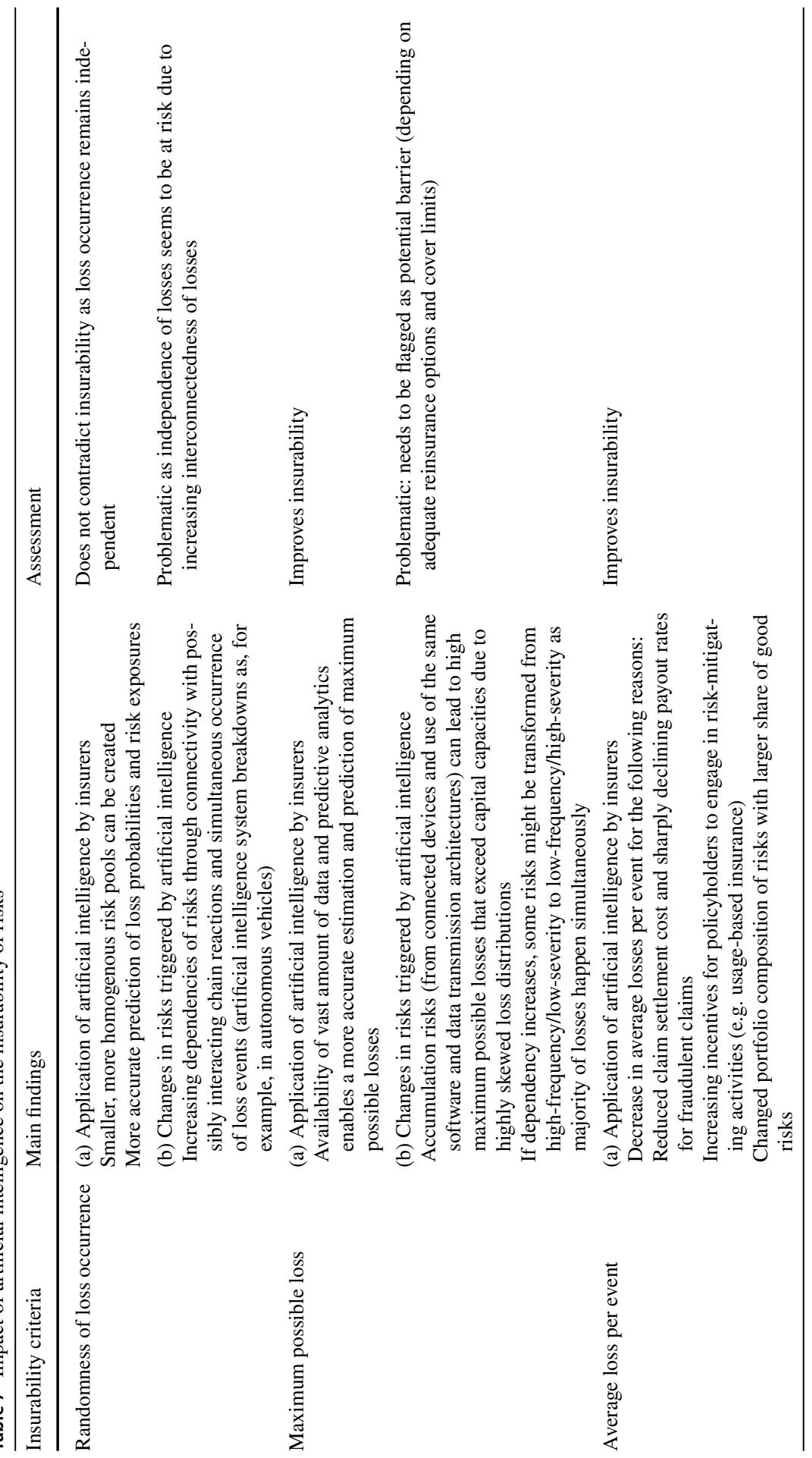

站。 


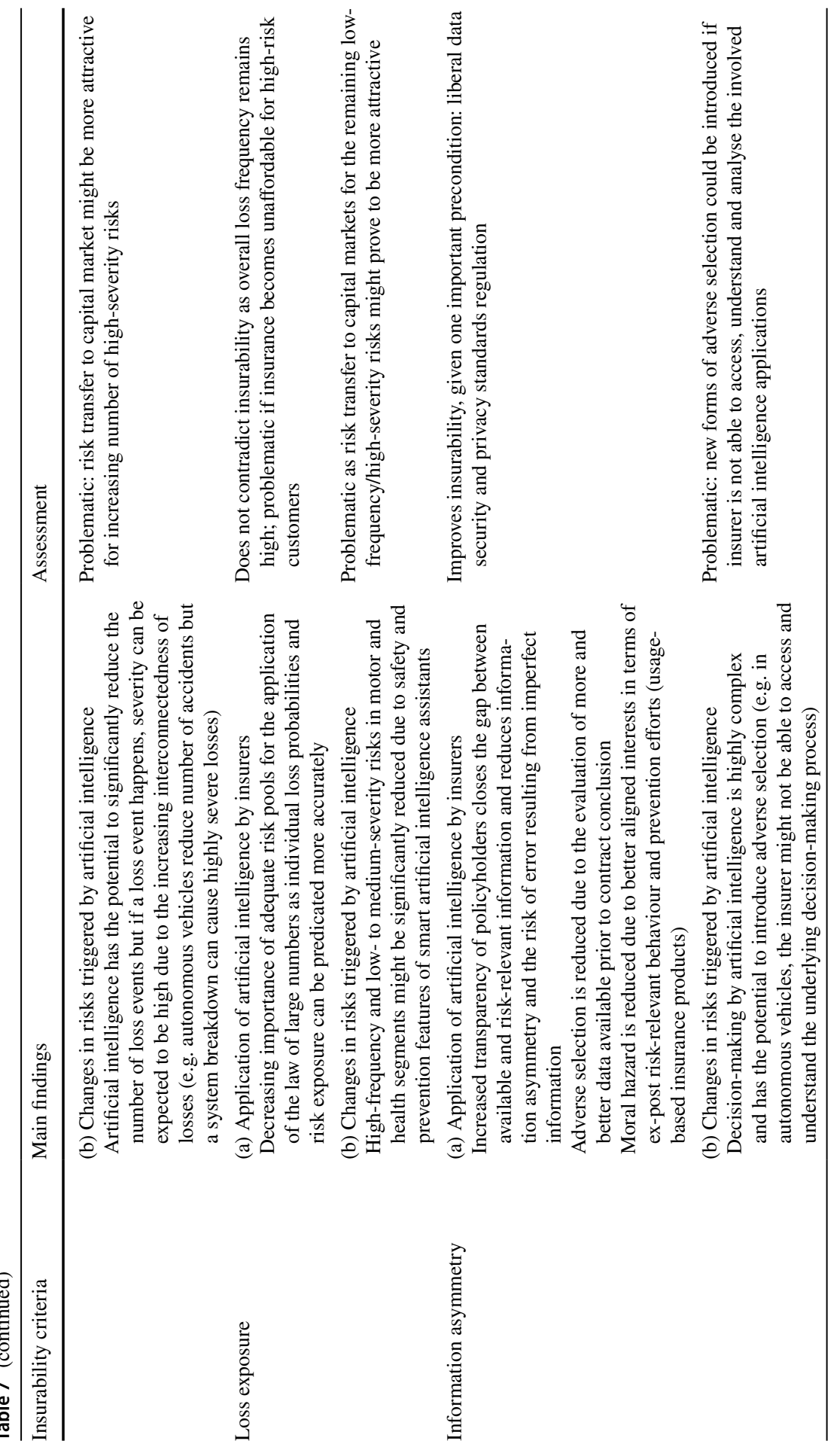




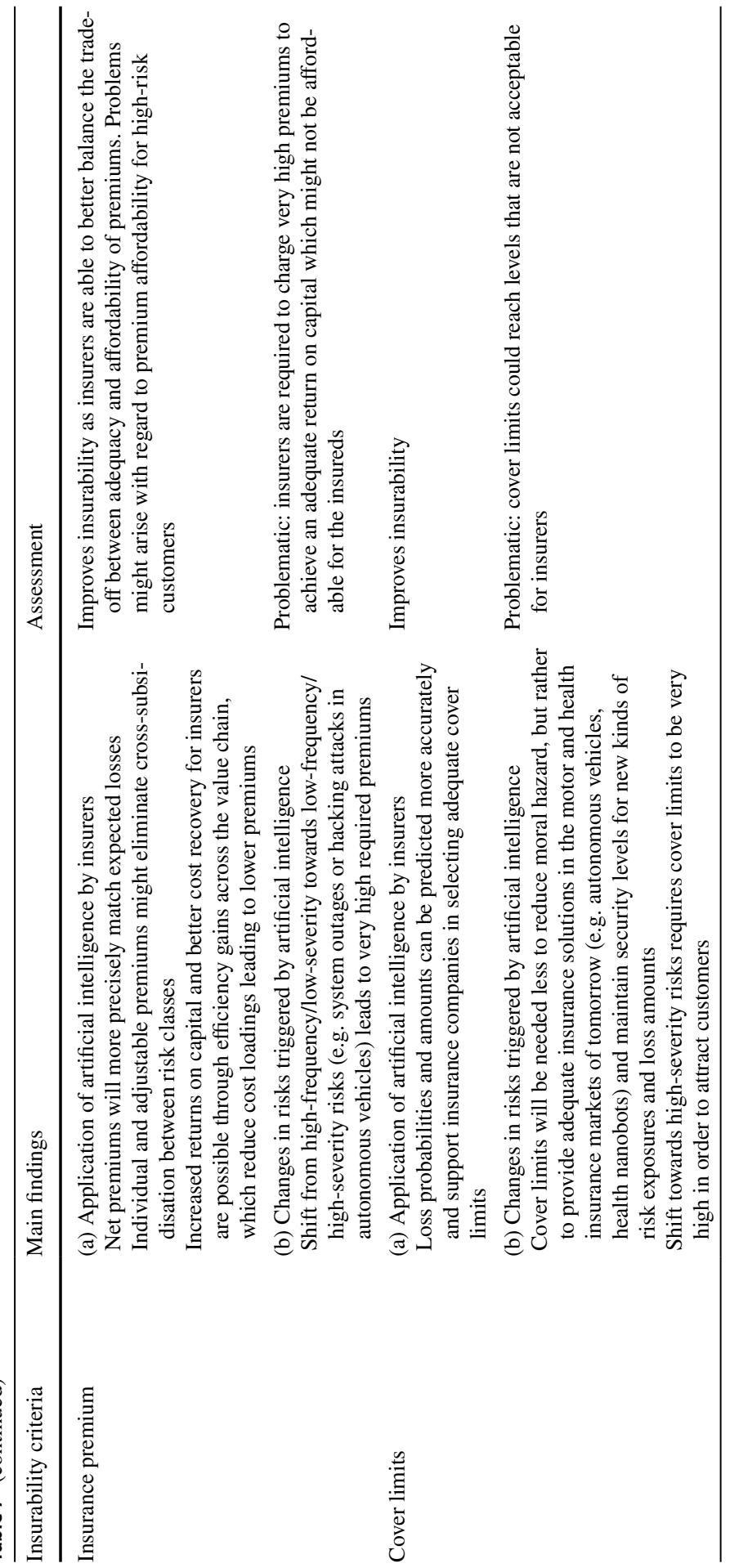

称。 


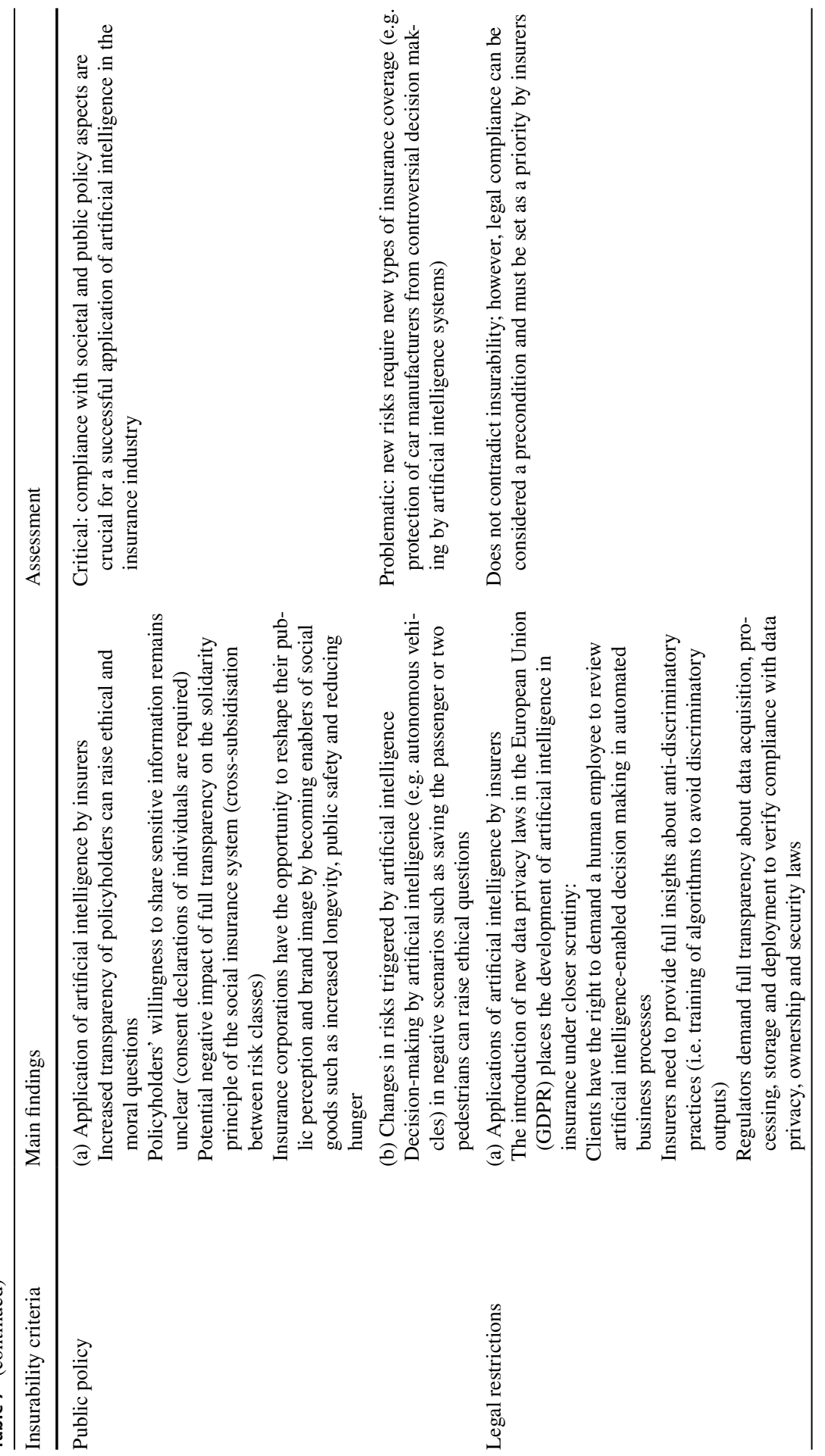




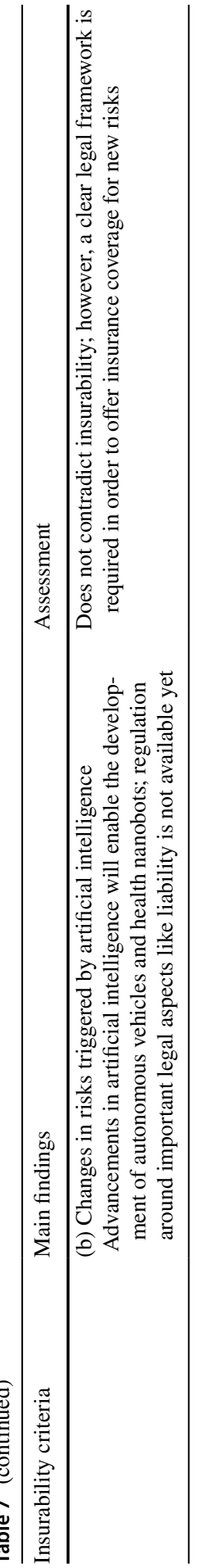

站。 
responsible data management can be considered a precondition for a successful implementation of artificial intelligence. Another critical precondition is public policy, especially social and ethical considerations. The problem of discrimination caused by artificial intelligence was recently demonstrated by Amazon's recruiting algorithm; its rating of candidates for software developer jobs showed bias against women. ${ }^{33}$ Hence, a transparent and anti-discriminatory application of artificial intelligence is crucial to gain the willingness of insureds to entrust their sensitive data to an insurer.

Finally, new risks become insurable with the implementation of artificial intelligence. Automated and continuous underwriting reduces transaction costs and will enable the extension of On-Demand insurance for various assets. Examples could include additional insurance coverage for personal belongings against theft or damage ${ }^{34}$ travel insurance and by-the-mile car insurance. Insurance coverage can thus be purchased for a wide range of low-severity risks for the time the asset is actually used and 'at risk'. Additionally, loss assessments of an insured event can be significantly accelerated by artificial intelligence, which accelerates the claims management process and the corresponding payments. Thereby, the most severe risks, such as crop insurance against natural disasters, can be covered by insurance companies. ${ }^{35}$ Consequently, artificial intelligence applications by insurers push the boundaries of insurability as several low- and high-severity risks become insurable.

\section{Changes in risks triggered by artificial intelligence}

The insurance market of the future will be shaped by numerous everyday artificial intelligence applications. For example, self-driving vehicles and healthcare with proactive, real-time and data-driven analysis of health status will emerge. This development will have a significant impact on the risk landscape and has two major implications for the insurability of risks. Artificial intelligence applications have the potential to transform the nature of loss events. Given the example of autonomous driving, the total number of accidents is likely to be considerably reduced, implying much lower loss probabilities (contradicts insurability criterion 4). However, a breakdown of the underlying artificial intelligence system or a hacking attack can cause a cascading series of accidents resulting in a considerable increase in the maximum possible loss (contradicts insurability criterion 2). Hence, loss events are not independent due to increasing connectedness (contradicts insurability criterion 1) and the shift from high-frequency/low-severity to low-frequency/high-severity risks. Similar concerns are discussed by Biener et al. (2015), who concluded that

\footnotetext{
33 See e.g. Dastin (2018).

34 Insuring certain assets against theft with an On-Demand insurance product could be especially attractive during a short vacation.

35 An example is the RIICE project, which provides satellite-based crop production monitoring. The assessment of an insured event can be completed more quickly and at relatively lower costs than the previous process of loss assessors travelling to the area and assessing the damage on site. See http://www. riice.org/about-riice/about-riice/.
} 
accumulation risk ${ }^{36}$ poses a major hurdle to the insurability of cyber risks. A potential way to reduce accumulation risk and ensure sufficient independency of loss events could be the diversification of applied artificial intelligence systems, which would improve insurability. High-severity risks also require very high cover limits and premium payments, which could contradict insurability criteria 6 and 7. Hence, insurance companies are challenged to revise traditional insurance coverage and design innovative insurance products.

In addition, ethical and legal aspects of artificial intelligence arise whenever algorithms have to make difficult decisions (e.g. whether a malfunctioning autonomous vehicle should strike a child or a group of adults, i.e. Foot's trolley problem, see e.g. Nyholm and Smids 2016), thereby raising liability issues (see e.g. Jarrahi 2018). Autonomous vehicles can demonstrate the potential safety problems related to artificial intelligence applications in everyday life. A fatal collision between an artificialintelligence-controlled Uber vehicle and a pedestrian in Arizona in 2018 exemplifies this statement (see e.g. National Transportation Safety Board 2019). Furthermore, the data processed in artificial intelligence algorithms and the obtained insights raise questions regarding data security and protection (i.e. data access and usage). The need to regulate companies that develop and use artificial intelligence is evident. The use of algorithms ranges from autonomous vehicles to decision support systems in the health sector, as well as in artificial-intelligence-powered weapon systems. National and international institutions are responsible for developing guidelines for a fair and appropriate handling of artificial intelligence applications. However, the demands for transparency, non-discrimination and fairness clearly show the limits of the application of artificial intelligence as some principal dilemmas cannot be resolved. For example, the way in which machine learning arrives at the respective conclusions has never been-and due to the technical peculiarities will never becompletely transparent. Another ethical dilemma arises in the context of the fairness of artificial intelligence. An activity that a company or public authority considers fair might not have to be fair from the perspective of the consumer or citizen.

Despite all these concerns, the enormous potential of artificial intelligence must not be ignored. There still has not been an appropriately broad discussion of the limitations and concerns that reflects the relevance of the topic. However, as the technology is already being implemented and will have a profound impact on our everyday life, urgent action is required.

\footnotetext{
36 Accumulation risk is the problem of emerging dependencies of risks through increasing interconnectedness. Given the scenario that all self-driving vehicles were manufactured by a few industry leaders and use the same software, algorithms and data infrastructure, a system breakdown, software malfunctions due to data transmission problems or cybercrime activities can paralyse city traffic and lead to simultaneous loss events in which all risks are dependent.
} 


\section{Summary and derivation of potential future work}

We provide an overview of various artificial intelligence applications within the insurance industry and analyse their impact along the insurance-specific value chain based on Porter (1985) and in light of the insurability criteria developed by Berliner (1982). Table 8 summarises the results of the three core topics discussed in the previous section. Based on these results, we identify potential areas of future work from both an academic and practical perspective.

The numerous entry points illustrate that artificial intelligence has the potential to change many activities across the insurance value chain. The main opportunities for value generation will evolve around process automation (leading to cost savings and thus margin expansion) and the use of additional customer insights for entering new revenue streams, acquiring new customers and more personalised interactions with existing customers (leading to revenue growth). Today, the adoption of artificial intelligence within insurance markets is in its earliest stages and the academic research on the implications of artificial intelligence on the insurance business model is still limited. However, the topic is attracting increasing attention and interest from practitioners worldwide, as illustrated by the rapidly growing and generously funded InsurTech sector. ${ }^{37}$ The present paper helps practitioners navigate their organisations to take full advantage of the benefits of artificial intelligence, and motivates academics to pave the way for a successful adoption of artificial intelligence by answering important research questions and running empirical analyses that go beyond the scope of this paper.

Today's artificial narrow intelligence systems are trained to perform only very specific tasks (e.g. a chess computer cannot play poker). Of course, weak artificial intelligence is not the ultimate goal of the tech companies that are investing billions of dollars in the development of the technology. They try to develop artificial general intelligence systems that are capable of abstract and creative thinking and making judgements under conditions of uncertainty (Uj 2018). Without knowing if the development of these artificial intelligence systems is actually possible, experts expect the first system to be ready in the next 10 to 30 years ( $\mathrm{Uj} 2018$ ). Given this vague time horizon, insurance managers, policymakers and regulators need to focus on the technology that is in place now (i.e. artificial narrow intelligence or weak AI). At the same time, it is important to track technological development and to continuously update potential management and regulatory frameworks in this dynamic field of research and practice.

From a scientific point of view, the changes in asymmetry of information and the associated economic welfare effects are intriguing. Linked to this is the question regarding the value of data from the customer's and provider's points of view. Thus, in the face of a latent fatalism in dealing with data, it is not quite clear what privacy is worth from the customer perspective (Biener et al. 2020). Positive effects of artificial intelligence applications on economic welfare can also be found in the

\footnotetext{
37 Total InsurTech funding volume has soared from USD 869 million in 2014 (94 deals) to over USD 6.3 billion (314 deals) in 2019 (CB Insights 2020).
} 
Table 8 Summary of results

\section{What is artificial intelligence and which applications will influence the insurance industry?}

Due to the complex nature and various perceptions of (human) intelligence, a commonly accepted definition of artificial intelligence does not exist; this paper follows the definition by Kelley et al. (2018) and understands artificial intelligence as 'a computer system that can sense its environment, learn, and take action from what it is learning'; the three types of artificial intelligence, categorised by their degree of intelligence, are narrow, general and super. Artificial narrow intelligence constitutes the status quo of machine intelligence; the method used to train algorithms and thus realise artificial intelligence is machine learning; in recent years, deep learning, as a subset of machine learning, has gained increasing attention

Key application fields: (1) conversion of language or text (voice/speech recognition, natural language generation, text analytics); (2) recognition of patterns, trends and preferences (pattern and anomaly detection, predictive analytics, recommendation engines); (3) computer vision and content-based processing of graphical information (image and video analysis, facial recognition and biometrics); (4) data-driven decision making (automatic decision making)

The status quo of artificial intelligence in the insurance industry is largely dominated by industry use cases, where artificial narrow intelligence is used for the (semi)-automation of routine and standard tasks across claims management, customer service and risk assessment; the impact of today's artificial intelligence applications in insurance can be mainly classified as 'operations efficacy and efficiency' investment cases; only a few insurers and InsurTechs are already using artificial intelligence for innovative discovery processes ('customer and operations discovery') to seize value creation opportunities with new products, in new markets, targeted to new clients

\section{What is the impact of artificial intelligence along the insurance-specific value chain?}

Today's artificial intelligence applications impact the entire insurance value chain from marketing through underwriting and pricing to asset and risk management. There are three major categories of change by artificial intelligence applications: (1) the way insurance companies interact with customers; (2) the automation of business processes and decision making; and (3) new markets and new risks that emerge with artificial intelligence

Insurers can profit from increased operational efficiency (cost reduction through artificial intelligenceenabled process automation mainly in underwriting and pricing as well as claim settlement, including improved fraud detection) as well as from revenue growth (artificial intelligence improving existing products and allowing the development of new, more personalised product offerings)

Insureds benefit from an improved customer experience through a more personalised and efficient interaction with the insurance company; more transparent and tailored product offerings; individualised premiums in innovative insurance products; a faster purchasing process; a seamless underwriting process reduces time and effort spent by insureds; $24 / 7$ available customer service through chatbots; more convenient claim reporting; faster claim assessment and claim payment; lower premiums due to cost reduction by the insurer

\section{How does artificial intelligence influence the insurability of risks?}

The assessment of the impact of artificial intelligence on the insurability of risks requires a clear distinction between the application of artificial intelligence by the insurers themselves and the changes in the risk landscape triggered through the implementation of artificial intelligence in insurance-related fields The application of artificial intelligence by insurers not only has the potential to generate value in multiple dimensions across the value chain but also improves the insurability of risks. Major improvements include a more accurate estimation of loss probabilities and loss amounts, more accurate risk assessments and continuously re-evaluated personalised premiums and the reduction of asymmetric information

However, expected advancements in artificial intelligence and their integration in insurance markets contradict several insurability criteria as they might transform some risks from low-severity/high-frequency to high-severity/low-frequency due to the accumulation risk as a result of increasing interconnectedness, which might negatively affect insurability (randomness of loss occurrence, maximum possible loss, loss exposure)

Increased policyholder transparency, constant monitoring and the availability of new sensitive customer information raise numerous legal and ethical questions about, for example, discrimination, safety, liability and data protection 
field of prevention at the collective level when it comes to better understanding large amounts of data and using them for the benefit of customers. On an individual level, however, welfare effects are not negligible, because there may be both winners and losers in digital monitoring by artificial intelligence systems.

Several shortcomings of this paper might motivate future research. One is the generalisation of the analysis to the entire insurance sector. This offers both practitioners and academics a sense of the scope of the topic, but it lacks accuracy and applicability, because insurance segments and product lines are heterogeneous. Consequently, a detailed analysis of artificial intelligence on single steps of the value chain for each major type of insurance or the evaluation of upcoming artificial intelligence trends (e.g. neural networks that pave the way to the development of artificial general intelligence) on the insurance sector could be interesting. Moreover, we show some future scenarios where insurers could become enablers of social good, like increased longevity and improved public safety. It would be interesting to analyse the role of the insurance sector in combatting significant societal challenges in health and elderly care. For example, a steadily increasing number of elderly people are living with chronic diseases and require personal care services. However, the number of care professionals and doctors is not keeping pace with the growth of this population. Research can include the role of artificial intelligence applications, such as health nanobots, tracking devices and chatbots, to support health and elderly care.

A second shortcoming is the analysis of insurability criteria, which are somewhat vague because of missing empirical evidence. Consequently, our assessment serves as an indicator of whether or not single criteria are likely to be contradicted by the implementation of artificial intelligence. So far, no academic studies have directly analysed the effects of artificial intelligence on important actuarial metrics such as adverse selection, moral hazard and risk pooling or market criteria. From a practitioner's perspective, the question is still open as to whether better risk-based calculation of premiums will lead to lower combined ratios as both losses and the collected premiums are expected to move in tandem. It might lead to better insurance products with higher customer value, but it is not entirely clear if artificial intelligence is Pareto-optimal in the sense that every client will profit from the increasing use of artificial intelligence. From a general welfare point of view, we would expect to profit if artificial intelligence reduced the number of claims, but there is no overall assessment yet. The paper also highlights the importance of societal insurability criteria, but a detailed analysis goes beyond the scope of this paper as several external factors are likely to be relevant.

Further thoughts have led us to the following open questions: What is the role of insurance companies when technology firms dominate access to data? How will insurance companies react if data and privacy regulation become more restrictive and prohibit the use of policyholders' personal information? Will self-driving vehicles and health nanobots transform risks to the extent that the traditional idea of insurance comes into question? Will the public perception and brand image of insurance companies suffer as people become uncomfortable with constant surveillance? Will increased transparency and usage-based pricing lead to less solidarity in the context of social insurance? Will this lead to social unrest if high-risk policyholders can no longer afford insurance? Or will good risks try to opt out of traditional insurance pools with 
cross-subsidisation across risk classes (e.g. in social security schemes)? These questions will have a direct impact on insurance corporations over the next few years, so it is important for insurance executives to start thinking about these scenarios today.

Funding Open Access funding provided by University of St. Gallen.

Open Access This article is licensed under a Creative Commons Attribution 4.0 International License, which permits use, sharing, adaptation, distribution and reproduction in any medium or format, as long as you give appropriate credit to the original author(s) and the source, provide a link to the Creative Commons licence, and indicate if changes were made. The images or other third party material in this article are included in the article's Creative Commons licence, unless indicated otherwise in a credit line to the material. If material is not included in the article's Creative Commons licence and your intended use is not permitted by statutory regulation or exceeds the permitted use, you will need to obtain permission directly from the copyright holder. To view a copy of this licence, visit http://creativecommons.org/licen ses/by/4.0/.

\section{References}

Abrardi, L., C. Cambini, and L. Rondi. 2019. The economics of artificial intelligence: A survey. Robert Schuman Centre for Advanced Studies Research Paper No. RSCAS 2019/58. https://doi. org/10.2139/ssrn.3425922.

Ahmed, M., A.N. Mahmood, and Md Rafiqul Islam. 2016. A survey of anomaly detection techniques in financial domain. Future Generation Computer Systems 55: 278-288. https://doi.org/10.1016/j. future.2015.01.001.

Albrecher, H., A. Bommier, D. Filipović, P. Koch-Medina, S. Loisel, and H. Schmeiser. 2019. Insurance: Models, digitalization, and data science. Swiss Finance Institute Research Paper No. 19-26. https:// doi.org/10.2139/ssrn.3382125.

Ayuso, M., M. Guillen, and J. Perch Nielsen. 2019. Improving automobile insurance ratemaking using telematics: Incorporating mileage and driver behaviour data. Transportation 46: 735-752. https:// doi.org/10.1007/s11116-018-9890-7.

Akhusama, P.M., and C. Moturi. 2016. Cloud computing adoption in insurance companies in Kenya. American Journal of Information Systems 4 (1): 11-16.

Allam, Z., and Z.A. Dhunny. 2019. On big data, artificial intelligence and smart cities. Cities 89: 80-91. https://doi.org/10.1016/j.cities.2019.01.032.

BarNir, A., J.M. Gallaugher, and P. Auger. 2003. Business process digitization, strategy, and the impact of firm age and size: The case of the magazine publishing industry. Journal of Business Venturing 18 (6): 789-814. https://doi.org/10.1016/S0883-9026(03)00030-2.

Barr, A., and E.A. Feigenbaum. 1981. The handbook of artificial intelligence, vol. 1. Stanford: HeurisTech Press.

Baum, S.D., B. Goertzel, and T.G. Goertzel. 2011. How long until human-level AI? Results from an expert assessment. Technological Forecasting and Social Change 78 (1): 185-195. https://doi. org/10.1016/j.techfore.2010.09.006.

Berliner, B. 1982. Limits of insurability of risks. Englewood Cliffs: Prentice-Hall.

Berliner, B. 1985. Large risks and limits of insurability. The Geneva Papers on Risk and InsuranceIssues and Practice 10 (37): 313-329. https://doi.org/10.1057/gpp.1985.22.

Bhatnagar, S., A. Alexandrova, S. Avin, S. Cave, L. Cheke, M. Crosby, J. Feyereisl, M. Halina, B.S. Loe, S.Ó. Éigeartaigh, F. Martínez-Plumed, H. Price, H. Shevlin, A. Weller, A. Winfield, and J. Hernández-Orallo. 2018. Mapping intelligence: Requirements and possibilities. In Philosophy and theory of artificial intelligence, ed. V.C. Müller, 117-135. Cham: Springer. https://doi.org/10.1007/978-3319-96448-5_13.

Biener, C., M. Eling, and J. Hendrik Wirfs. 2015. Insurability of cyber risk: An empirical analysis. The Geneva Papers on Risk and Insurance-Issues and Practice 40 (1): 131-158. https://doi. org/10.1057/gpp.2014.19. 
Biener, C., M. Eling, and M. Lehmann. 2020. Balancing the desire for privacy against the desire to hedge risks. Journal of Economic Behavior \& Organization. https://doi.org/10.1016/j.jebo.2020.03.007.

Bohnert, A., A. Fritzsche, and S. Gregor. 2019. Digital agendas in the insurance industry: The importance of comprehensive approaches. The Geneva Papers on Risk and Insurance-Issues and Practice 44 (1): 1-19. https://doi.org/10.1057/s41288-018-0109-0.

Bologa, A.-R., R. Bologa, and A. Florea. 2013. Big data and specific analysis methods for insurance fraud detection. Database Systems Journal 4 (4): 30-39.

Bolton, C., V. Machová, M. Kovacova, and K. Valaskova. 2018. The power of human-machine collaboration: Artificial intelligence, business automation, and the smart economy. Economics, Management, and Financial Markets 13 (4): 51-56. https://doi.org/10.22381/emfm13420184.

Boyd, R., and R.J. Holton. 2017. Technology, innovation, employment and power: Does robotics and artificial intelligence really mean social transformation? Journal of Sociology 54 (3): 331-345. https:// doi.org/10.1177/1440783317726591.

Braun, A., and F. Schreiber. 2017. The current InsurTech landscape: Business models and disruptive potential. St. Gallen: Institute of Insurance Economics I.VW-HSG, University of St. Gallen.

Brown, J.R., and A. Goolsbee. 2002. Does the internet make markets more competitive? Evidence from the life insurance industry. Journal of Political Economy 110 (3): 481-507. https://doi. org/10.1086/339714.

Bughin, J., E. Hazan, S. Ramaswamy, M. Chui, T. Allas, P. Dahlström, N. Henke, and M. Trench. 2017. Artificial intelligence - the next digital frontier? London: McKinsey Global Institute. Accessed 28 August 2020. https://www.calpers.ca.gov/docs/board-agendas/201801/full/day1/06-technology -background.pdf.

Cappiello, A. 2020. The technological disruption of insurance industry: A review. International Journal of Business and Social Science 11: 1.

Castelvecchi, D. 2016. Can we open the black box of AI? Nature 538 (7623): 20-23. https://doi. org/10.1038/538020a.

Catlin, T., J.-T. Lorenz, J. Nandan, S. Sharma, and A. Waschto. 2018. Insurance beyond digital: The rise of ecosystems and platforms. McKinsey \& Company. Accessed 28 August 2020. https://www. mckinsey.com/industries/financial-services/our-insights/insurance-beyond-digital-the-rise-of-ecosy stems-and-platforms.

CB Insights. 2020. Insurance tech Q2 2020. Accessed 28 August 2020. https://www.cbinsights.com/resea rch/report/insurance-tech-q2-2020/.

Charpentier, A. 2007. Insurability of climate risks. The Geneva Papers on Risk and Insurance-Issues and Practice 33 (1): 91-109. https://doi.org/10.1057/palgrave.gpp.2510155.

Churchland, P.S., and T.J. Sejnowski. 1988. Perspectives on cognitive neuroscience. Science 242 (4879): 741-745. https://doi.org/10.1126/science.3055294.

Dale, R. 2016. The return of the chatbots. Natural Language Engineering 22 (5): 811-817. https://doi. org/10.1017/s1351324916000243.

Dastin., J. 2018. Amazon scraps secret AI recruiting tool that showed bias against women. Accessed 28 August 2020. https://www.reuters.com/article/us-amazon-com-jobs-automation-insight/amazo n-scraps-secret-ai-recruiting-tool-that-showed-bias-against-women-idUSKCN1MK08G.

Deloitte. 2017. Artificial intelligence: From mystery to mastery - unlocking the business value of AI in the insurance industry. Accessed 28 August 2020. https://www2.deloitte.com/de/de/pages/innovation/ contents/artificial-intelligence-insurance-industry.html.

Eastman, J.K., A.D. Eastman, and K.L. Eastman. 2002a. Insurance sales agents and the internet: The relationship between opinion leadership, subjective knowledge, and internet attitudes. Journal of Marketing Management 18 (3-4): 259-285. https://doi.org/10.1362/0267257022872460.

Eastman, J.K., A.D. Eastman, and K.L. Eastman. 2002b. Issues in marketing online insurance products: An exploratory look at agents' use, attitudes, and views of the impact of the internet. Risk Management and Insurance Review 5 (2): 117-134. https://doi.org/10.1111/1098-1616.00013.

Eling, M., and M. Lehmann. 2018. The impact of digitalization on the insurance value chain and the insurability of risks. The Geneva Papers on Risk and Insurance-Issues and Practice 43: 359-396. https://doi.org/10.1057/s41288-017-0073-0.

Erevelles, S., N. Fukawa, and L. Swayne. 2016. Big data consumer analytics and the transformation of marketing. Journal of Business Research 69 (2): 897-904. https://doi.org/10.1016/j.jbusr es.2015.07.001.

Faloon, M., and B. Scherer. 2017. Individualization of robo-advice. The Journal of Wealth Management 20 (1): 30-36. https://doi.org/10.3905/jwm.2017.20.1.030. 
Garven, J.R. 2002. On the implications of the internet for insurance markets and institutions. Risk Management and Insurance Review 5 (2): 105-116. https://doi.org/10.1111/1098-1616.00014.

Gatteschi, V., F. Lamberti, C. Demartini, C. Pranteda, and V. Santamaría. 2018. Blockchain and smart contracts for insurance: Is the technology mature enough? Future Internet 10 (2): 20-35. https:// doi.org/10.3390/fi10020020.

Gehrke, E. 2014. The insurability framework applied to agricultural microinsurance: What do we know, what can we learn? The Geneva Papers on Risk and Insurance-Issues and Practice 39 (2): 264279. https://doi.org/10.1057/gpp.2014.2.

Gentsch, P. 2018. Künstliche Intelligenz für Sales, Marketing und Service: Mit AI und Bots zu einem Algorithmic Business - Konzepte und Best Practices. Wiesbaden: Springer Gabler. https://doi. org/10.1007/978-3-658-25376-9.

Goodfellow, I., Y. Bengio, and A. Courville. 2016. Deep learning. Cambridge, MA: MIT Press.

Görz, G., J. Schneeberger, and U. Schmid. 2013. Handbuch der Künstlichen Intelligenz, 5th ed. Munich: Oldenbourg.

Graves, A., A.-R. Mohamed, and G. Hinton. 2013. Speech recognition with deep recurrent neural networks. 2013 IEEE International Conference on Acoustics, Speech and Signal Processing. https:// doi.org/10.1109/icassp.2013.6638947.

Grewal, D.S. 2014. A critical conceptual analysis of definitions of artificial intelligence as applicable to computer engineering. IOSR Journal of Computer Engineering 16 (2): 9-13. https://doi. org/10.9790/0661-16210913.

Guidotti, R., A. Monreale, S. Ruggieri, F. Turini, F. Giannotti, and D. Pedreschi. 2018. A survey of methods for explaining black box models. ACM Computing Surveys 51 (5): 93. https://doi. org/10.1145/3236009.

He, K., X. Zhang, S. Ren, and J. Sun. 2016. Deep residual learning for image recognition. 2016 IEEE Conference on Computer Vision and Pattern Recognition (CVPR): 770-778. https://doi. org/10.1109/cvpr.2016.90.

Hussain, K., and E. Prieto. 2016. Big data in the finance and insurance sectors. In New horizons for a data-driven economy - A roadmap for usage and exploitation of big data in Europe, ed. J.M. Cavanillas, E. Curry, and W. Wahlster, 209-223. Cham: Springer.

International Association of Insurance Supervisors. 2017. FinTech developments in the insurance industry. Accessed 28 August 2020. https://www.iaisweb.org/page/news/other-papers-and-reports/ file/65625/report-on-fintech-developments-in-the-insurance-industry.

Jajal, T.D. 2018. Distinguishing between narrow AI, general AI and super AI. Accessed 28 August 2020. https://medium.com/@tjajal/distinguishing-between-narrow-ai-general-ai-and-super-ai-a4bc4 4172e22.

Jakšič, M., and M. Marinč. 2019. Relationship banking and information technology: The role of artificial intelligence and FinTech. Risk Management 21 (1): 1-18. https://doi.org/10.1057/s4128 3-018-0039-y.

Jarrahi, M.Hossein. 2018. Artificial intelligence and the future of work: Human-AI symbiosis in organizational decision making. Business Horizons 61 (4): 577-586. https://doi.org/10.1016/j.busho r.2018.03.007.

Jiang, F., Y. Jiang, H. Zhi, Y. Dong, H. Li, S. Ma, Y. Wang, Q. Dong, H. Shen, and Y. Wang. 2017. Artificial intelligence in healthcare: Past, present and future. Stroke and Vascular Neurology 2 (4): 230-243. https://doi.org/10.1136/svn-2017-000101.

Kaiser, T. 2002. The customer shall lead: e-business solutions for the new insurance industry. The Geneva Papers on Risk and Insurance-Issues and Practice 27 (1): 134-145.

Kaplan, A., and M. Haenlein. 2019. Siri, Siri, in my hand: Who's the fairest in the land? On the interpretations, illustrations, and implications of artificial intelligence. Business Horizons 62 (1): 15-25. https://doi.org/10.1016/j.bushor.2018.08.004.

Kelley, K.H., L.M. Fontanetta, M. Heintzman, and N. Pereira. 2018. Artificial intelligence: Implications for social inflation and insurance. Risk Management and Insurance Review 21 (3): 373-387. https ://doi.org/10.1111/rmir.12111.

Kharpal, A. 2017. Stephen Hawking says A. I. could be 'worst event in the history of our civilization'. Accessed 28 August 2020. https://www.cnbc.com/2017/11/06/stephen-hawking-ai-could-be-worst -event-in-civilization.html.

Knight, W. 2017. The dark secret at the heart of AI. MIT Technology Review 120 (3): 54-61.

Kothari, D. 2019. How artificial intelligence accelerates software development. International Research Journal of Engineering and Technology (IRJET) 6 (8): 1392-1394. 
KPMG. 2018. Neues Denken, Neues Handeln. Insurance Thinking Ahead: Versicherungen im Zeitalter von Digitalisierung und Cyber, Studienteil B: Cyber. Accessed 28 August 2020. https://asset s.kpmg/content/dam/kpmg/ch/pdf/neues-denken-neues-handeln-cyber-de.pdf.

Kreutzer, R.T., and M. Sirrenberg. 2020. Künstliche Intelligenz verstehen: Grundlagen - Use-Cases Unternehmenseigene KI-Journey. Wiesbaden: Springer Gabler. https://doi.org/10.1007/978-3-65825561-9.

Krizhevsky, A., I. Sutskever, and G.E. Hinton. 2017. ImageNet classification with deep convolutional neural networks. Communications of the ACM 60 (6): 84-90. https://doi.org/10.1145/3065386.

Lake, B.M., T.D. Ullman, J.B. Tenenbaum, and S.J. Gershman. 2016. Building machines that learn and think like people. Behavioral and Brain Sciences. https://doi.org/10.1017/s0140525x16001837.

LeCun, Y., Y. Bengio, and G. Hinton. 2015. Deep learning. Nature 521 (7553): 436-444. https://doi. org/10.1038/nature14539.

Lee, J., H. Davari, J. Singh, and V. Pandhare. 2018. Industrial artificial intelligence for industry 4.0based manufacturing systems. Manufacturing Letters 18: 20-23. https://doi.org/10.1016/j.mfgle t.2018.09.002.

Legner, C., T. Eymann, T. Hess, C. Matt, T. Böhmann, P. Drews, A. Mädche, N. Urbach, and F. Ahlemann. 2017. Digitalization: Opportunity and challenge for the business and information systems engineering community. Business \& Information Systems Engineering 59 (4): 301-308. https://doi. org/10.1007/s12599-017-0484-2.

Li, B.-H., B.-C. Hou, W.-T. Yu, X.-B. Lu, and C.-W. Yang. 2017. Applications of artificial intelligence in intelligent manufacturing: A review. Frontiers of Information Technology \& Electronic Engineering 18 (1): 86-96. https://doi.org/10.1631/FITEE.1601885.

Lorenz, Johannes-Tobias, Ulrike Deetjen, and Jasper van Ouwerkerk. 2020. Ecosystems in insurance: The next frontier for enhancing productivity. McKinsey \& Company. Accessed 28 August 2020. https:// www.mckinsey.com/industries/financial-services/our-insights/insurance-blog/ecosystems-in-insur ance-the-next-frontier-for-enhancing-productivity.

Lycett, M. 2013. 'Datafication': Making sense of (big) data in a complex world. European Journal of Information Systems 22 (4): 381-386. https://doi.org/10.1057/ejis.2013.10.

Majchrzak, A., M.L. Markus, and J. Wareham. 2016. Designing for digital transformation: Lessons for information systems research from the study of ICT and societal challenges. MIS Quarterly 40 (2): 267-277. https://doi.org/10.25300/misq/2016/40:2.03.

Makridakis, S. 2017. The forthcoming artificial intelligence (AI) revolution: Its impact on society and firms. Futures 90: 46-60. https://doi.org/10.1016/j.futures.2017.03.006.

Marblestone, A.H., G. Wayne, and K.P. Kording. 2016. Toward an integration of deep learning and neuroscience. Frontiers in Computational Neuroscience. https://doi.org/10.3389/fncom.2016.00094.

Marchand, A., and P. Marx. 2020. Automated product recommendations with preference-based explanations. Journal of Retailing. https://doi.org/10.1016/j.jretai.2020.01.001.

Martínez-Plumed, F., B.S. Loe, P. Flach, S.O. Éigeartaigh, K. Vold, and J. Hernández-Orallo. 2018. The facets of artificial intelligence: A framework to track the evolution of AI. Proceedings of the Twenty-Seventh International Joint Conference on Artificial Intelligence. https://doi.org/10.24963/ ijcai.2018/718.

McCarthy, J. 2007. What is artificial intelligence? Stanford: Stanford University. Accessed 28 August 2020. http://www-formal.stanford.edu/jmc/whatisai.pdf.

McCulloch, W.S., and W. Pitts. 1943. A logical calculus of the ideas immanent in nervous activity. The Bulletin of Mathematical Biophysics 5: 115-133. https://doi.org/10.1007/bf02478259.

Monett, D., and C.W.P. Lewis. 2018. Getting clarity by defining artificial intelligence-A survey. In Philosophy and theory of artificial intelligence 2017, ed. V.C. Müller, 212-214. Berlin: Springer. https ://doi.org/10.1007/978-3-319-96448-5_21.

Müller, M. 2002. Computer Go. Artificial Intelligence 134 (1-2): 145-179. https://doi.org/10.1016/s0004 $-3702(01) 00121-7$.

National Transportation Safety Board. 2019. Collision between vehicle controlled by developmental automated driving system and pedestrian: Accident report. Accessed 28 August 2020. https://www. ntsb.gov/investigations/AccidentReports/Reports/HAR1903.pdf.

Neisser, U., G. Boodoo, T.J. Bouchard Jr., A.W. Boykin, N. Brody, S. Ceci, D.F. Halpern, J.C. Loehlin, R. Perloff, R.J. Sternberg, and S. Urbina. 1996. Intelligence: Knowns and unknowns. American Psychologist 51 (2): 77-101. https://doi.org/10.1037/0003-066X.51.2.77. 
Niu, J., W. Tang, F. Xu, X. Zhou, and Y. Song. 2016. Global research on artificial intelligence from 1990-2014: Spatially-explicit bibliometric analysis. ISPRS International Journal of Geo-Information 5 (5): 66. https://doi.org/10.3390/ijgi5050066.

Nyholm, S., and J. Smids. 2016. The ethics of accident-algorithms for self-driving cars: An applied trolley problem? Ethical Theory and Moral Practice 19 (5): 1275-1289. https://doi.org/10.1007/s1067 7-016-9745-2.

Panetta, K. 2018. 5 trends emerge in the Gartner hype cycle for emerging technologies. Accessed 28 August 2020. https://www.gartner.com/smarterwithgartner/5-trends-emerge-in-gartner-hype-cycle -for-emerging-technologies-2018/.

Patel, V.L., E.H. Shortliffe, M. Stefanelli, P. Szolovits, M.R. Berthold, R. Bellazzi, and A. Abu-Hanna. 2009. The coming of age of artificial intelligence in medicine. Artificial Intelligence in Medicine 46 (1): 5-17. https://doi.org/10.1016/j.artmed.2008.07.017.

Porter, M. 1985. The competitive advantage: Creating and sustaining superior performance. New York: The Free Press.

Rahlfs, C. 2007. Redefinition der Wertschoepfungskette von Versicherungsunternehmen. Wiesbaden: Deutscher Universitäts-Verlag.

Rangwala, A., A. Starrs, E. Viale, D. Presutti, J. Bramblet, K. Saldanha, and N. Shibata. 2020. Technology vision for insurance 2020: We, the post-digital people. Can your enterprise survive the "techclash?” Accenture. Accessed 28 August 2020. https://financialservices.accenture.com/rs/368RMC-681/images/Accenture-Technology-Vision-for-Insurance-2020-Full-Report.pdf.

Rawat, W., and Z. Wang. 2017. Deep convolutional neural networks for image classification: A comprehensive review. Neural Computation 29 (9): 2352-2449. https://doi.org/10.1162/neco_a_00990.

Redmon, J., and A. Farhadi. 2017. YOLO9000: Better, faster, stronger. 2017 IEEE Conference on Computer Vision and Pattern Recognition (CVPR). https://doi.org/10.1109/cvpr.2017.690.

Ren, S., K. He, R. Girshick, and J. Sun. 2017. Faster R-CNN: Towards real-time object detection with region proposal networks. IEEE Transactions on Pattern Analysis and Machine Intelligence 39 (6): 1137-1149. https://doi.org/10.1109/tpami.2016.2577031.

Riikkinen, M., H. Saarijärvi, P. Sarlin, and I. Lähteenmäki. 2018. Using artificial intelligence to create value in insurance. International Journal of Bank Marketing 36 (6): 1145-1168. https://doi. org/10.1108/ijbm-01-2017-0015.

Russell, S., and P. Norvig. 2012. Künstliche Intelligenz: Ein moderner Ansatz, 3rd ed. Munich: Pearson Education.

Sicari, S., A. Rizzardi, L.A. Grieco, and A. Coen-Porisini. 2015. Security, privacy and trust in Internet of Things: The road ahead. Computer Networks 76: 146-164. https://doi.org/10.1016/j. comnet.2014.11.008.

Silver, D., A. Huang, C.J. Maddison, A. Guez, L. Sifre, G. van den Driessche, J. Schrittwieser, I. Antonoglou, V. Panneershelvam, M. Lanctot, et al. 2016. Mastering the game of Go with deep neural networks and tree search. Nature 529 (7587): 484-489. https://doi.org/10.1038/natur e16961.

Stoeckli, E., C. Dremel, and F. Uebernickel. 2018. Exploring characteristics and transformational capabilities of InsurTech innovations to understand insurance value creation in a digital world. Electronic Markets 28 (3): 287-305. https://doi.org/10.1007/s12525-018-0304-7.

The Geneva Association. 2018. Insurance in the digital age: A view on key implications for the economy and society. Author: Christian Schmidt. September. Accessed 28 August 2020. https:// www.genevaassociation.org/sites/default/files/research-topics-document-type/pdf_public/insur ance_in_the_digital_age_01.pdf.

Thrall, J.H., X. Li, Q. Li, C. Cruz, S. Do, K. Dreyer, and J. Brink. 2018. Artificial intelligence and machine Learning in radiology: Opportunities, challenges, pitfalls, and criteria for success. Journal of the American College of Radiology 15 (3): 504-508. https://doi.org/10.1016/j. jacr.2017.12.026.

Topol, E.J. 2019. High-performance medicine: The convergence of human and artificial intelligence. Nature Medicine 25 (1): 44-56. https://doi.org/10.1038/s41591-018-0300-7.

Turing, A.M. 1950. Computing machinery and intelligence. Mind 59 (236): 433-460. https://doi. org/10.1093/mind/lix.236.433.

$\mathrm{Uj}$, A. 2018. Understanding three types of artificial intelligence. Accessed 28 August 2020. https:// www.analyticsinsight.net/understanding-three-types-of-artificial-intelligence/.

Vial, G. 2019. Understanding digital transformation: A review and a research agenda. The Journal of Strategic Information Systems 28 (2): 118-144. https://doi.org/10.1016/j.jsis.2019.01.003. 
vom Brocke, J., A. Simons, B. Niehaves, K. Reimer, R. Plattfaut, and A. Cleven. 2009. Reconstructing the giant: on the importance of rigour in documenting the literature search process. ECIS 2009 Proceedings 161. http://aisel.aisnet.org/ecis2009/161.

Wang, P. 2008. What do you mean by “AI”? In Artificial general intelligence 2008, ed. P. Wang, B. Goertzel, and S. Franklin, 362-373. Amsterdam: IOS Press.

Wang, P. 2019. On defining artificial intelligence. Journal of Artificial General Intelligence 10 (2): 1-37. https://doi.org/10.2478/jagi-2019-0002.

Webster, J., and R.T. Watson. 2002. Analyzing the past to prepare for the future: Writing a literature review. MIS Quarterly 26 (2): 13-23.

Young, T., D. Hazarika, S. Poria, and E. Cambria. 2018. Recent trends in deep learning based natural language processing. IEEE Computational Intelligence Magazine 13 (3): 55-75. https://doi. org/10.1109/mci.2018.2840738.

Yu, K.-H., A.L. Beam, and I.S. Kohane. 2018. Artificial intelligence in healthcare. Nature Biomedical Engineering 2 (10): 719-731. https://doi.org/10.1038/s41551-018-0305-z.

Yu, S., S. Jia, and C. Xu. 2017. Convolutional neural networks for hyperspectral image classification. Neurocomputing 219: 88-98. https://doi.org/10.1016/j.neucom.2016.09.010.

Yuan, X., P. He, Q. Zhu, and X. Li. 2019. Adversarial examples: Attacks and defenses for deep learning. IEEE Transactions on Neural Networks and Learning Systems 30 (9): 2805-2824. https:// doi.org/10.1109/tnnls.2018.2886017.

Zhang, Q., Z. Yu, W. Shi, and H. Zhong. 2016. Demo abstract: EVAPS: Edge video analysis for public safety. 2016 IEEE/ACM Symposium on Edge Computing (SEC): 121-122. https://doi. org/10.1109/sec.2016.30.

Publisher's Note Springer Nature remains neutral with regard to jurisdictional claims in published maps and institutional affiliations.

\section{About the authors}

Martin Eling is Professor of Insurance Management and Director of the Institute of Insurance Economics at the University of St. Gallen, Switzerland. He received his doctorate from the University of Münster, Germany and his habilitation from the University of St. Gallen. In 2008 he was Visiting Professor at the University of Wisconsin-Madison. From 2009 to 2011, he was Professor for Insurance at the University of Ulm, Germany.

Davide Nuessle received a master's degree in Banking and Finance from the University of St. Gallen, Switzerland. In addition, he studied at the San Diego State University, USA, where he received an M.Sc. in Applied Mathematics.

Julian Staubli received a bachelor degree in Business Administration from the University of St. Gallen, Switzerland, and is currently pursuing the Master of Arts in Banking and Finance at the same university. In addition, he studied at the Hong Kong University of Science and Technology. 